\title{
Parental Alcohol Consumption and Adult Children's Educational Attainment*
}

\author{
Lucia Mangiavacchi $^{\dagger} \quad$ Luca Piccoli ${ }^{\ddagger}$
}

October 6, 2017

\begin{abstract}
This study analyses whether an excessive parental alcohol consumption during childhood can affect long run children's educational attainments. Using 19 waves of the Russia Longitudinal Monitoring Survey (RLMS), where individuals and their families are followed from childhood to adulthood, this study analyses parental alcohol consumption during childhood (between 1994 and 2001) and its relation with children's educational attainment about twelve years later (from 2005 to 2014). Panel estimations show that mother's excessive alcohol consumption during childhood is consistently negatively associated with children educational outcomes, as years of education, the highest education grade achieved and the probability of having a tertiary education degree, a finding that is robust to possible endogeneity issues. In particular, while moderate drinking is not an issue, an additional standard glass of vodka (15.57 grams of pure alcohol) consumed by the mother per day, reduces years of education by almost one year (0.88), and by 5.8 percentage points (or about $27 \%$ ) the probability of having a university degree. Similarly, mothers' alcohol consumption increase the probability of lower education grades and reduces that of having higher education. The study also explores the transmission mechanisms suggested by the literature, identifying a significant role for prenatal exposure to alcohol and, to a lesser extent, for intergenerational transmission of drinking habits.
\end{abstract}

JEL codes: D1, I1, I2, I3.

Keywords: alcohol consumption, children education, parents problem-drinking, RLMS, Russia.

\footnotetext{
${ }^{*}$ The paper has benefited from the valuable comments and suggestions of Ana Balsa, Massimiliano Bratti, Nadia Campaniello, Margherita Comola, Giorgia Giovannetti, Giovanni Mastrobuoni, William Nillsson, Steven Stillman, Inna Tsener and conference participants at 30th Annual Conference of the European Society for Population Economics (ESPE) in Berlin, 31st annual Conference of the Italian Association of Labour Economists (AIEL) in Trento, the Third SITES/IDEAs Annual Conference in Florence and seminar participants at University of Perugia. Financial support of the Spanish Ministry of Economy and Competitiveness, through grant ECO2015-63727-R, is gratefully acknowledged.

${ }^{\dagger}$ Corresponding author. Department of Applied Economics, Universitat de les Illes Balears, Crt Valldemossa km. 7.5, Palma de Mallorca, Spain. E-mail: lucia.mangiavacchi@uib.es

${ }^{\ddagger}$ Department of Applied Economics, Universitat de les Illes Balears, Crt Valldemossa km. 7.5, Palma de Mallorca, Spain. E-mail: luca.piccoli@uib.es
} 


\section{Introduction}

An extensive body of economic research has examined the consequences associated with the problem-drinking subject: for example, productivity losses (Renna, 2007; Böckerman et al., 2017), health (Chatterji et al., 2004) and educational costs (Cook and Moore, 1993; Renna, 2008; Chatterji, 2006; Balsa et al., 2011; Carrell et al., 2011). Problem-drinking as family issue is receiving also attention in economic literature since one member alcohol abuse may cause serious health and socio-economic consequences also for other family members with welfare losses in the short and long run. Menon et al. (2017), for instance, have recently shown that one partner's alcohol consumption is associated with intra-household inequality and gender discrimination. ${ }^{1}$ Other research has found the association between parental alcohol abuse and sons' and daughters' behavioural problems (Chatterji and Markowitz, 2001; Ajilore et al., 2016), health issues (Snow Jones et al., 1999; Fertig and Watson, 2009; Balsa and French, 2012), poor nutritional status (Hanć et al., 2015) and less parental supervision during childhood and adolescence (Snow Jones et al., 1999; Giannelli et al., 2013). Children of alcoholics are frequently studied in the psychological domain and found to experience common symptoms such as low self-esteem, loneliness, guilt, feelings of helplessness, fear of abandonment, and chronic depression. ${ }^{2}$ These psychological disorders may also hamper future life economic outcomes as education or participation into the labour market.

There are indeed few attempts in the economic literature to explore possible long-run consequences of parental problem drinking during childhood. Christoffersen and Soothill (2003) use register data from 84,765 children born in Denmark in 1966 followed between 1979 and 1993 and find that parental abuse of alcohol increased mortality, self-destructive behaviors (e.g. attempted suicide or drug addiction), hospitalization due to violence, risk of teenage pregnancy and unemployment. Balsa (2008) found intergenerational costs of parental problem-drinking in terms of labour market outcomes in adulthood analysing the 1979 cohort of the National Longitudinal Survey of Youth in US. Her results highlight the important losses in productivity suffered by adult children of alcoholics, which are manifested through lower labour force participation and lower wages. More recently, Nilsson (2017) showed that a temporary increase in alcohol availability in

\footnotetext{
${ }^{1}$ In double earners couples the husband obtains a larger share of the household resource cake, especially in low income households with a heavy drinker.

${ }^{2}$ The costs that a problem-drinking parent inflicts upon children are deeply studied in the psychological literature, where there is extensive evidence suggesting that children of alcoholic parents suffer from a range of negative outcomes in cognitive (Poon et al., 2000; Leonard and Eiden, 2002), behavioural (Connolly et al., 1993; Mattson and Riley, 1998; Marshal et al., 2007), psychological (Barber and Gilbertson, 1999; Cuijpers et al., 1999; Serec et al., 2012), emotional (Connell and Goodman, 2002) and social domains (Hussong et al., 2005, 2007; Keller et al., 2008). All this studies underline also the importance of the gender of the parent and the child as demographic factors. Disruptive behaviour, such as aggressiveness, hyperactivity and mental health problems, are particularly apparent in sons of parents who drink excessive amount of alcohol (Connolly et al., 1993; Hussong et al., 2007). Girls tend to display more internalising problems, such as poor self-concept, eating disorders, anxiety and depression (Hussong et al., 2005). Most studies examining outcomes for children of problem drinking parents have focused on paternal alcohol consumption due to the fact that women are less likely to engage in alcohol misuse and there may be insufficient number of observations to detect the impact of maternal drinking. One exception is the epidemiological research that supports an association between the excessive consumption of alcohol by women who are pregnant and the risk of foetal alcohol syndrome, since Jones and Smith (1973).
} 
Sweden during the late 1960s negatively affects labour market and educational outcomes of those children prenatally exposed.

Christoffersen and Soothill (2003) and Balsa (2008) study parental problem drinking not distinguishing the gender of the parent while Nilsson (2017) focuses only on mothers since his objective is the in utero alcohol exposure. None of the three studies use observed amount of parental alcohol consumption; Christoffersen and Soothill (2003) uses register data on hospitalizations associated with long-term alcohol abuse as a proxy of problem-drinking, Balsa (2008) relies on retrospective informations on parental problem drinking while Nilsson (2017) estimates the impact of the exposure to an alcohol availability policy. The objective of our work is in line with these three previous articles, however we look at the impact of observed amounts of alcohol consumed by fathers and mothers. Using 19 waves of the Russia Longitudinal Monitoring Survey (RLMS), where individuals and their families are followed from childhood to adulthood, we analyse whether paternal and maternal alcohol consumption during childhood (between 1994 and 2001) have long terms effects on children's educational record about twelve years later (from 2006 to 2014).

Russia is a relevant setting to study intergeneration transmission of problem-drinking consequences. The demand for alcohol has habits elements and low price elasticities, ${ }^{3}$ and, even during the Soviet regime, alcohol consumption was the third leading cause of death (Baltagi and Geishecker, 2006). Consequences and causes of the significant increase of alcohol consumption during the 90s have been extensively studied in the literature. Alcohol consumption was one of the main causes of increased mortality among young and middle aged men during the transition decades (Zohoori et al., 1998; Brainerd and Cutler, 2005) and it doubled among women at the beginning of transition (Zohoori et al., 1998). In addition, Baltagi and Geishecker (2006) suggests that the use of Russian data for alcohol demand analysis reduces measurement error in the explanatory variable (and the consequent estimation bias) since the social stigma related to alcohol consumption is weaker with respect to other countries and this should reduce the likelihood of misreporting by problem-drinkers.

To establish a relationship between mother's and father's problem-drinking and adult children educational achievements, measured by years of education, the highest level of education achieved, and the probability of obtaining a a tertiary education degree, we use different panel data models. The use of panel estimators helps reducing biases possibly arising from purely cross-sectional estimates and permits linking adult child situations to parents and children characteristics in the past, taking advantage of a direct measurement instead of using retrospective information. This feature permits avoiding the bias arising from a likely non-random measurement error typical of retrospective informations provided by a selected group, such as the children of alcoholic parents or problem-drinking adult children.

\footnotetext{
${ }^{3}$ Herzfeld et al. (2014) estimate a dynamic demand function of alcohol between 1994 and 2005, finding that older men drinks more than younger, and that alcohol consumption increases with income and decreases with education. Problem drinking is positively associated with fear and psychic stress of possible loosing job in regions most affected by unemployment but it is not directly affected by job lost.
} 
Even in a longitudinal estimation and controlling for a wide range of health, socio-economic and labour market variables, the identification of the effects of parental alcohol consumption on children's human capital development may suffer of endogeneity because unobserved family circumstances or individual attitudes of parents and children may be correlated and may influence both parental alcohol consumption and children's schooling achievements in the long run. This endogeneity arises from the correlation of parental alcohol consumption variables with the random individual specific effect. To address this source of endogeneity, in absence of a sufficiently strong instrument, we rely on an estimator proposed by Lewbel (2012) that exploit the heteroscedasticity generated by an unobserved common factor under assumption that some regressors are uncorrelated with the product of heteroscedastic error terms.

Results suggest a significant intergenerational costs of parental problem-drinking in terms of human capital development. In particular mother total grams of alcohol consumption during childhood is consistently negatively associated with years of education, the highest level of education achieved and the probability of having an university degree. These results are retained when controlling for the possible endogeneity arising from the correlation of parental drinking variable with the individual specific effect.

Since we are studying long term relations and possible resilience of childhood stressful events on future life outcomes, we explore which are the main mediators of these effects. ${ }^{4}$ In terms of transmission channels, the psychological literature (Connell and Goodman, 2002) identified four mechanisms that link parental problem-drinking with children outcomes: i) genetics, through an increased probability of being a problem-drinker; ii) exposure to the parent's behaviour and knowledge, with a higher likelihood to develop psychological and behavioural problems; iii) environmental stressors such as economic pressure, marital conflict, and disruption that are more common in a home with an alcoholic or problem-drinking parent; and iv) complications during prenatal development, which may affect cognitive and physical skills of the child.

The results suggest that the most important channel is through pre-natal exposure to excessive amounts of alcohol, in line with Nilsson (2017). Own consumption is a far less important mediator, while the other channels play a little role in transmitting the negative effects of parental drinking. Anyway, taking all the mediators analysed together, it is possible to explain only about 30-35\% of the negative effect of maternal alcohol consumption and the unexplained part may be due either by the quality of variables chosen as proxies of the transmission mechanisms or by the impossibility to test other mediators with the available data.

Our contribution to the literature is threefold. First the study addresses for the first time the causal relationship between parental problem drinking after birth and long run children's educational attainment. Second, this paper improves the econometric identification of the intergeneration costs of parental drinking: by making use of observational data instead of retrospective information on parental alcohol consumption and controlling for the unobserved heterogeneity is-

\footnotetext{
${ }^{4}$ The literature on cognitive and non cognitive skills formation has shown the importance of the observation of proper mediators to study the impact of childhood circumstances and events on future life outcomes (Cunha et al., 2010; Heckman et al., 2013).
} 
sues using an instrumental variable estimator. A third novelty is the possibility to directly inspect proxies of the transmission mechanisms of parental alcohol consumption on human capital development identified by the psychological and medical literature.

The rest of the paper is organized as follows. Section 2 describes the empirical strategy, including a discussion on possible identification issues and the mediation analysis. Section 3 details the data, sample selection and variables used in the empirical analysis. Section 4 presents the results and Section 5 concludes.

\section{Empirical strategy}

The main objective of the analysis is to verify whether long run educational attainment of children can be harmed by parental drinking during childhood. The empirical strategy adopted to asses the impact of parental drinking and the related potential endogeneity issues are described in the first part of the section, while the second part outlines the empirical strategy used to analyse the transmission mechanisms that make parental drinking potentially harmful for the offspring's educational attainment.

\subsection{Impact evaluation of parental drinking}

To asses the impact of parental drinking we use three different educational outcomes: years of education $\left(y e_{i t}\right)$, the highest education grade achieved $\left(e g_{i t}\right)$, and holding a tertiary education degree $\left(t e_{i t}\right)$. For each individual $i$, repeated observations of each outcome is available at different time $t$, thus suggesting the use of panel estimators. The main variables of interest, however, i.e. grams of alcohol consumed by the father and the mother during childhood, are time invariant, thus Fixed Effect (FE) estimators cannot be used. Instead, the appropriate Random-Effect (RE) model is applied to each outcome. In particular, the linear RE model is applied to years of education $\left(y e_{i t}\right)$, the RE Ordered Logit is applied to the highest education grade $\left(e g_{i t}\right)$, and the RE Logit is applied to tertiary education $\left(t e_{i t}\right)$. Analytically, these models are specified as:

$$
\left\{y e_{i t}, e g_{i t}, t e_{i t}\right\}=\alpha_{i}+a l c_{i}^{\prime} \beta+\operatorname{par}_{i}^{\prime} \gamma+a d u_{i t}^{\prime} \delta+g e o_{i}^{\prime} \eta+\epsilon_{i t},
$$

where $a l c_{i}$ is the set of time-invariant variables that describe parental drinking behaviour during childhood (in years 1994-2001), par $_{i}$ is a set of time-invariant variables that includes parents' and household characteristics during childhood, ad $u_{i t}$ is a set of child characteristics measured when adult, and geo $_{i}$ is a set of time-invariant geographical indicators. $\alpha_{i}$ and $\epsilon_{i t}$ are respectively the random individual-specific effect and the idiosyncratic error.

All three models are estimated with five different specifications: the first includes only parents' alcohol variables $\left(a l c_{i}\right)$; the second adds other parental characteristics $\left(\right.$ par $\left._{i}\right)$; the third adds adult child variables $\left(a d u_{i t}\right)$; the last adds geographical variables $\left(g e o_{i}\right)$. The stability of coefficients across different specifications is typically evidence of robust estimates and that possible endogeneity issues, discussed below, might produce relatively small biases. 
The identification of coefficients of maternal and paternal alcohol consumption in models (1) may be affected by endogeneity issues even in a panel estimation. Endogeneity would arise because of two main reasons: (i) unobserved individual attitudes of parents and children may be correlated and may influence both parental alcohol consumption and long run children's educational attainment: this implies a potential correlation between parental alcohol consumption regressors and the individual-specific effect $\alpha_{i}$; (ii) unobserved family circumstances may increase the likelihood that a parent becomes a problem-drinker and at the same time increase the probability that the child has lower educational achievements in the long run (Balsa, 2008). Again, this would imply correlation between parental alcohol variables and the individual specific effect $\alpha_{i}$. An important feature of the data used, i.e. the availability of direct observation of the family during childhood, allows us to control for several parents and children circumstances during the period 1994-2001, substantially reducing the likelihood of suffering of endogeneity. ${ }^{5}$

The ideal way to fully address the remaining potential endogeneity is to use an Instrumental Variable approach. In this respect we tested several instruments proposed by the literature on alcohol consumption: alcohol average prices and variability at district and regional level, district level vodka price growth rate in waves V to VII (as a proxy for local governmental vodka price control policies that were allowed from 1994 to 1998), district level alcohol mortality rates variations in 1914 (following an anti-alcohol governmental campaign in 1913), and having diabetes. None of them was sufficiently strong. Our interpretation of the poor performance of these instruments is that alcohol consumption in Russia is quite inelastic and not sensitive to exogenous changes (as previously showed by Herzfeld et al., 2014) since it is a cultural trait of Russian society and its purchase is frequently substituted by home made production. ${ }^{6}$ In addition, in Russia high levels of alcohol consumption are widespread, and not correlated with belonging to a specific socio-economic group, especially in the nineties as shown by Figure 1. This, together with previous evidence of a relatively weak social stigma associated to alcohol consumption, suggests that drinking behaviour may not be typically associated with worse economic outcomes by the population (for example to worse paid jobs), reducing the severity of endogeneity issues.

In absence of a proper instrumental variable, we test three alternative estimators with the objective of further strengthening the causal validity of the effect of parental alcohol consumption on long run educational attainment of the offspring. The first is an estimator proposed by Lewbel (2012) and Baum et al. (2017). The main idea is that identification is still possible when some regressors are uncorrelated with the product of heteroscedastic errors, which is the case when

\footnotetext{
${ }^{5}$ Balsa (2008) identifies an additional source of endogeneity deriving from the retrospective information about parents' problem drinking, which may be correlated with the time-varying component of the idiosyncratic error term. The idea is that problem drinking children are more likely to declare that their parents were also problem drinkers, implying an endogeneity bias driven by reverse causality. This source of endogeneity, however, does not apply to our study because parental drinking variables are time-invariant and a direct observation of parents' behaviour during childhood, which is not contemporaneous to children's educational outcomes about twelve years later, and thus uncorrelated with the time-varying idiosyncratic component of the error term.

${ }^{6}$ A recent study by Ajilore et al. (2016) confirms that alcohol consumption among adolescents is insensitive to price changes in the US as well.
} 
Figure 1: Father's alcohol consumption in 1994-2001 and father's socio-economic status (Local Polynomial Regression)

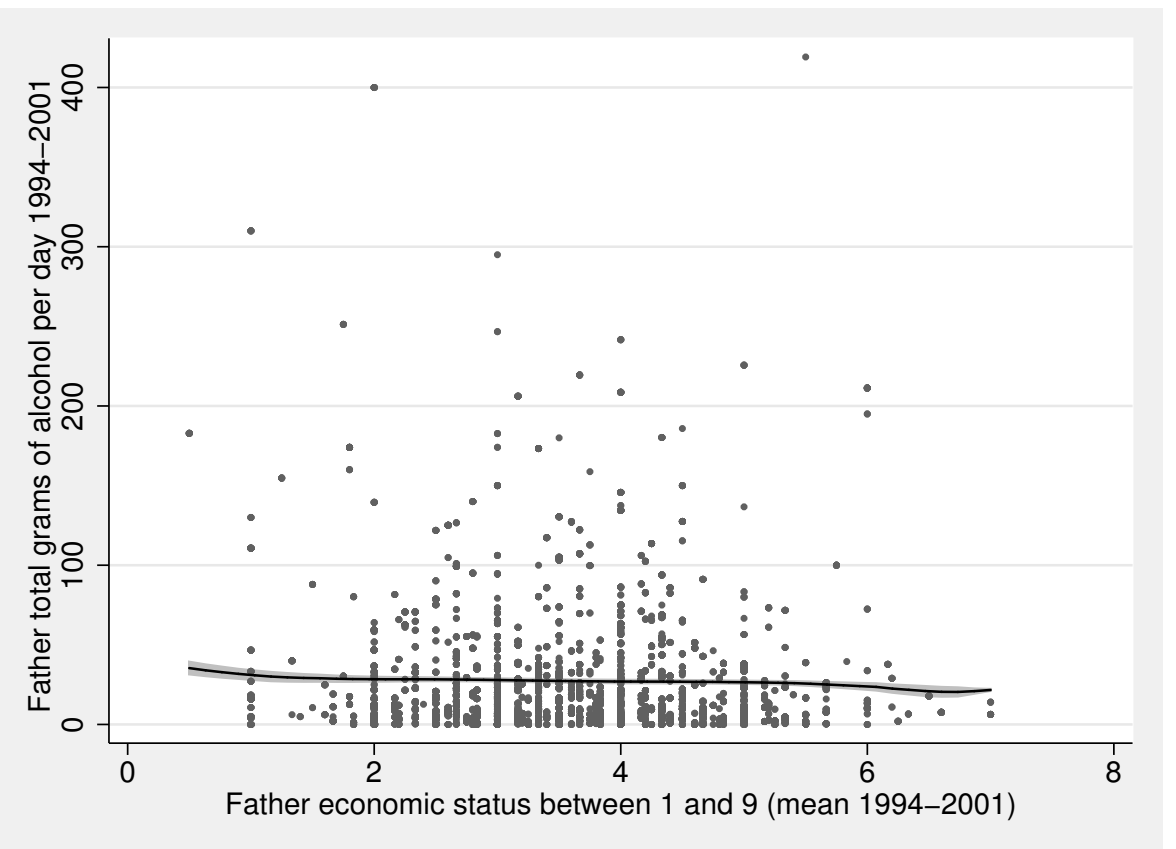

error correlations are due to unobserved common factor. ${ }^{7}$ This appears to be exactly the case under investigation, as discussed earlier. We then exploit the possibilities offered by hybrid models, which allow correlation between explanatory variables and the individual effect $\alpha_{i}$. In this respect, two different estimators are applied.

The first hybrid model is an extension of the RE estimator proposed by Mundlak (1978) that allows for correlation between the individual effect and time-varying variables. With respect to the standard RE model, this extension includes among the regressors a vector of the individual specific longitudinal mean of time-varying variables. If the Mundlak model is well specified, the coefficients of time-varying variables equal those of the FE estimator, but at variance with the FE, it is still possible to estimate the coefficients of time invariant regressors. The Mundlak extensions are similar to models presented in (1), with the individual effect specified as

$$
\alpha_{i}=\overline{a d u}_{i}^{\prime} \pi+\xi_{i}
$$

The second, proposed by Hausman and Taylor (1981), is an IV estimator that uses the values of exogenous time-varying regressors in periods other than the current as instruments for the endogenous time invariant regressors and a FE estimator for the coefficients of time varying variables. The Hausman-Taylor estimator requires to distinguish between regressors uncorrelated with the individual specific effect and those potentially correlated, and assumes that all explanatory

\footnotetext{
${ }^{7}$ Cost of using this estimator in our analysis it that we are losing the panel structure of the data.
} 
variables are uncorrelated with $\epsilon_{i t}$.

\subsection{Mediation}

Once established a causal relation between parental alcohol consumption during childhood, and long run educational attainment of the offspring, we aim at investigating which are the transmission mechanisms that are in place, given that parental drinking would unlikely produce such negative effects per se. To this aim we follow the causal mediation analysis proposed by Imai et al. (2010) as implemented for linear and Probit models in Hicks et al. (2011).

Typically, mediation analysis is developed to asses the mechanisms through which a treatment impacts on an outcome, and the causal mediation analysis bases on the framework of potential outcomes (for a detailed description, see Imai et al., 2010). The impact of a treatment $T=1$ on an outcome $Y$, or average treatment effect (ATE), in this framework is typically defined as $E\left\{Y_{i}(T=1)-Y_{i}(T=0)\right\}$, while the mediation analysis seeks to quantify which part of this impact acts through a particular mechanism. If $M_{i}(t)$ is the potential value of a mediator of interest when the treatment is $T_{i}=t, Y_{i}(t, m)$, denotes the potential outcome when the treatment takes value $T_{i}=t$ and the mediator $M_{i}=m$. Thus, the observed outcome depends on the treatment and on the mediator, which in turn depends on the treatment, i.e. $Y_{i}\left\{T_{i}, M\left(T_{i}\right)\right\}$. The amount of impact mediated by the mechanism of interest, or average causal mediation effect (ACME), is defined as $E\left\{Y_{i}\left(t, M_{i}(1)\right)-Y\left(t, M_{i}(0)\right)\right\}$. The proportion of the total effect mediated by the mechanism of interest can be easily computed as $A C M E / A T E$. The identification of the ACME requires the sequential ignorability assumption to hold, which states that i) given pretreatment confounders, treatment assignment is ignorable (unconfoundedness); and that ii) given the the actual treatment status and pretreatment confounders, the observed mediator is ignorable (Imai et al., 2010).

Respect to standard causal mediation analyses, the present study presents two peculiarities: i) the treatment is not a binary variable, but rather a continuous variable (parental amount of alcohol consumed during childhood), and ii) two treatments are jointly analysed, that is alcohol consumption of the mother and the father. For issue i), it is still possible to use the method proposed by Hicks et al. (2011) with a continuous treatment, but it is necessary to specify at which value of the continuous variable the treatment is equal to 1 . We propose two different values, the median of the conditional distribution of the amount of alcohol consumed in a day, which

includes moderate drinking, and the one corresponding to the $90^{\text {th }}$ percentile, which instead is meant to capture only problem drinking. As to problem ii) we only perform the mediation analysis for mother's alcohol consumption, which at variance with father's consumption, is robustly significantly impacting long run children educational attainment. 


\section{Data and sample selection}

The empirical analysis is based on nineteen waves (from round V to XXIII, spanning from 1994 to 2014) of the Russia Longitudinal Monitoring Survey (RLMS-HSE). ${ }^{8}$ Households participating in the survey were selected trough a multi-stage probability sampling procedure in order to guarantee cross-sectional national representativeness. Within each selected primary sample unit, the population was stratified into urban and rural substrata in order to guarantee representativeness of the sample in both areas. The data covers approximately 5,000 households, 12,000 adults and 2,000 children per wave.

The RLMS permits the identification of the relationship between each member in the household and children are still followed by the survey when they become adult and form their own families (through their individual identification code which remains unchanged). In this way, it is possible to observe the educational achievements (together with other contemporary characteristics and behaviours) of an adult child and to link it with his/her past behaviours and characteristics, and to those of his/her parents.

\subsection{Sample selection}

Data on adult children (contemporary variables) is taken from rounds XV to XXIII, while parents and children data is taken from rounds $\mathrm{V}$ to $\mathrm{X}$. The data structure is thus individual based and composed by two panel periods, separated by a four waves gap. The outcomes of interest pertain to the second panel period but the most relevant explanatory variables are from the first period and are treated as time invariant in the second period by computing their average value for each individual. This reduces measurement error and minimizes the impact on the data of the labour market behavioural responses to institutional and economic changes occurred between 1994 and $2001 .{ }^{9}$ In the second period the temporal structure is maintained in order to take advantage of panel data estimation techniques.

For the objective of the study, the sample is restricted to adults in waves XV-XXIII that were observed and living with at least one of their parent(s) in waves V-X. This results in a sample of 1,740 individuals and 8,534 observations, a very small fraction (about 5\%) of the total sample for the same waves, which includes 36,169 individuals and 137,943 observations. They are aged between 18 and 37 years old and their average age is 23.4 . About $23.2 \%$ of them are married or cohabiting (see Table 1). Parental alcohol consumption is observed when they were on average between 7 and 14 years old and conditionally averages at 5.3 grams of pure alcohol per day for the mother and 29.6 grams for the father.

The fact that the sample selection implies such a strong reduction in the sample size rises the question about the national representativeness of the results. It is worth noting that for this

\footnotetext{
${ }^{8}$ The survey is conducted by the Higher School of Economics and ZAO Demoscop together with the Carolina Population Center, University of North Carolina at Chapel Hill and the Institute of Sociology RAS. More information can be found in the RLMS-HSE site: http://www.cpc.unc.edu/projects/rlms-hse.

${ }^{9}$ The first six waves cover a period of 8 years because data were not collected in 1997 and 1999.
} 
Table 1: Descriptive Statistics of Main Variables

\begin{tabular}{|c|c|c|}
\hline & Mean & Standard deviation \\
\hline \multicolumn{3}{|l|}{ Dependent variables } \\
\hline Years of education & 16.521 & 4.033 \\
\hline Has a university degree & 0.216 & 0.412 \\
\hline Highest education grade & 3.304 & 1.181 \\
\hline \multicolumn{3}{|l|}{ Parental variables in 1994-2001 } \\
\hline Mother total grams of alcohol per day (conditional mean) & 5.262 & 12.727 \\
\hline Father total grams of alcohol per day (conditional mean) & 29.625 & 40.655 \\
\hline Mother drank & 0.800 & 0.400 \\
\hline Father drank & 0.741 & 0.438 \\
\hline Mother wage rate (mean) & 1.075 & 0.885 \\
\hline Mother work status (mean) & 0.698 & 0.364 \\
\hline Father wage rate (mean) & 0.957 & 1.009 \\
\hline Father work status (mean) & 0.621 & 0.424 \\
\hline Mother had a univesrity degree & 0.208 & 0.406 \\
\hline Father had a univesrity degree & 0.156 & 0.363 \\
\hline Father not present & 0.210 & 0.407 \\
\hline Mother not present & 0.017 & 0.130 \\
\hline Mother did not have Russian nationality & 0.040 & 0.197 \\
\hline Father did not have Russian nationality & 0.039 & 0.195 \\
\hline Mother's age at birth & 25.791 & 5.061 \\
\hline Father's age at birth & 27.780 & 4.698 \\
\hline Number of siblings (other children) & 1.177 & 1.177 \\
\hline Lived mostly in a rural settlement & 0.258 & 0.438 \\
\hline \multicolumn{3}{|l|}{ Adult child variables in $2006-2014$} \\
\hline Total grams of alcohol per day (conditional mean) & 10.438 & 76.294 \\
\hline Age & 23.415 & 3.860 \\
\hline Age at round $\mathrm{X}$ & 14.309 & 3.787 \\
\hline Older than 22 & 0.541 & 0.498 \\
\hline Male & 0.502 & 0.500 \\
\hline Cohabiting (not married) & 0.021 & 0.144 \\
\hline Married & 0.230 & 0.421 \\
\hline Number of children & 0.336 & 0.607 \\
\hline Chronic illness & 0.264 & 0.441 \\
\hline Non Russian nationality & 0.134 & 0.341 \\
\hline Metropolitan areas: Moscow and St. & 0.058 & 0.233 \\
\hline Northern and North Western & 0.062 & 0.242 \\
\hline Central and Central Black-Earth & 0.176 & 0.381 \\
\hline Volga-Vaytski and Volga Basin & 0.178 & 0.383 \\
\hline North Caucasian & 0.200 & 0.400 \\
\hline Ural & 0.174 & 0.379 \\
\hline Western Siberian & 0.078 & 0.268 \\
\hline Eastern Siberian and Far Eastern & 0.074 & 0.262 \\
\hline \multicolumn{3}{|l|}{ Mediators } \\
\hline Mother drank while pregnant in 1994-2001 & 0.0123 & 0.1102 \\
\hline Parents have divorced in $2002-2004$ & 0.0562 & 0.2304 \\
\hline Average grams of alcohol in 2002-2004 & 8.5055 & 19.8152 \\
\hline Helped parents during adolescence (14-17 years old) & 0.0357 & 0.1856 \\
\hline Fequency of having had health probelms in 1994-2001 & 0.2921 & 0.3038 \\
\hline Observations & 8,538 & \\
\hline Number of ind. & 1,740 & \\
\hline
\end{tabular}


Table 2: Descriptive Statistics of Main Variables

\begin{tabular}{lcccc}
\hline & \multicolumn{2}{c}{ Selected sample } & \multicolumn{2}{c}{ Representative sample } \\
& Mean & s.d. & Mean & s.d. \\
\hline Age & 23.205 & 3.227 & 23.712 & 3.353 \\
Sex & 0.504 & 0.500 & 0.457 & 0.498 \\
Non Russian nationality & 0.158 & 0.364 & 0.125 & 0.331 \\
Economic satisfaction (ladder) & 4.268 & 1.323 & 4.162 & 1.368 \\
Married & 0.230 & 0.421 & 0.356 & 0.479 \\
Years of education, recoded & 16.590 & 4.058 & 16.901 & 4.004 \\
Has a univesrity degree & 0.229 & 0.420 & 0.238 & 0.426 \\
Number of children & 0.302 & 0.548 & 0.480 & 0.709 \\
Wage rate & 55.247 & 74.625 & 55.821 & 325.036 \\
Total grams of alcohol per day & 6.933 & 13.315 & 7.250 & 22.573 \\
Income decile & 6.630 & 2.743 & 6.452 & 2.764 \\
& & & & \\
N. obs & 984 & & 2202 & \\
\hline
\end{tabular}

study, national representativeness is ruled out by design of the RLMS. Indeed, if on one hand it allows long run individual analyses because it follows individuals also when they move or form a new family, once this happen they are excluded from the representative sample and their sample weight is set to zero. Because in our sample movers are more than $42 \%$, it is impossible to claim any national representativeness of the results. Nevertheless, it is still possible to compare some key characteristics of the sample with a similar one composed of individuals who are in the representative sample. To make a comparable sample, we select individuals in round XIX (the median in the range XV XIII) aged $18-29^{10}$ both in the selected and representative sample.

Table 2 shows the mean values and standard deviations of a selection of variables comparing the selected sample and a similarly aged sample of representative individuals drawn from the full dataset. Although differences exist (and would be often statistically significant) in the two samples, a first look clearly reveals that differences are generally small, with some exceptions. First, the selected sample is slightly younger. Then, the selected sample is more gender balanced, with a larger share of non-Russian individuals, a lower proportion of married individuals and with less children with respect to the representative sample. However, education levels, wage, economic position and satisfaction, and alcohol consumption are very close in the two samples.

What follows presents a descriptive analysis of all the variables included in models (1), of which descriptive statistics are provided in Table 1.

\subsection{Educational outcomes}

As anticipated in Section 2, the educational outcomes of interest are three: years of education, tertiary education and education grade.

The first outcome, years of education $y e_{i t}$, is a continuous variable constructed by the Carolina Polulation Center starting from several individual declarations on education, such as the level of

\footnotetext{
${ }^{10}$ Although older individuals are in the selected sample, up to 33 years in wave XIX, their frequency is much lower than in the representative sample and would have influenced the comparison of means.
} 
Table 3: Years of education, recoded

\begin{tabular}{cl}
\hline Values & Corresponding education level \\
\hline 0 & 0 years of general schooling \\
1 & 1 year of general schooling \\
2 & 2 years of general schooling \\
3 & 3 years of general schooling \\
4 & 4 years of general schooling \\
5 & 5 years of general schooling \\
6 & 6 years of general schooling \\
7 & 7 years of general schooling \\
8 & 8 years of general schooling \\
9 & 9 years of general schooling \\
10 & Incomplete secondary (7-9) plus some PTU \\
11 & Incomplete secondary (7-9) \& PTU diploma \\
12 & 10 or more years of general schooling without diploma \\
13 & Incomplete secondary plus less than two years of tekhnikum \\
14 & Secondary school diploma by any means \\
15 & 10 or more years of secondary plus vocational without degree \\
16 & 10 or more years of secondary plus vocational diploma \\
17 & 2 or more years of tekhnikum without diploma \\
18 & Tekhnikum with diploma \\
19 & Higher education 1-2 years \\
20 & Higher education (3 or more years) \\
21 & Higher education with diploma \\
22 & Incomplete advanced \\
23 & Advanced with diploma \\
\hline
\end{tabular}

study completed (also partially), to build a proper ladder of educational attainment of individual $i$ at time $t$. Table 3 clearly shows that the values taken by the variable do not exactly correspond to years of schooling, which explains the unexpectedly large mean value observed in Table 1.

Having tertiary education degree, $t e_{i, t}$, is a dummy variable equal to 1 if the adult child $i$ has a university degree at time $t$. In the selected sample, the variable takes value 1 in $21.6 \%$ of cases, although being a panel some individuals get the degree on the way. The proportion of individuals that get a university degree by 2014 is $25.6 \%$.

Finally, the highest education grade achieved is a categorical ordinal variable taking values "1" for primary education, "2" for secondary education, "3" for vocational training "4" for being enrolled at university, "5" for university degree, and "6" for postgraduate degree. The average in our sample is 3.3 , but more informative is the composition. In particular, about $2 \%$ of individuals only had primary education in the last wave, $26.9 \%$ have secondary education, $26.3 \%$ a vocational training, $19 \%$ is enrolled at university, $25.1 \%$ has a university degree and $0.5 \%$ a postgraduate degree.

\subsection{Alcohol variables}

Since the RLMS was originally designed to monitor the health impact of economic transition in Russia, it contains detailed information on alcohol consumption of the respondents for all waves, so it is possible to measure parental amount of alcohol consumption, as well as children own consumption later in life. Individual alcohol consumption is self-reported by the respondent in 
the health module. In Russia, alcohol consumption is measured in grams instead of litres, so each respondent is asked to declare how many grams of beer, wine, fortified wine, home-made liquor, vodka, and other alcoholic beverages they usually drink per day during the last 30 days. Following Baltagi and Geishecker (2006), these amounts are adjusted for pure alcohol content in order to make the various types of alcoholic beverages comparable and then summed up to compute total individual alcohol consumption. The weights used are $5 \%$ for the alcohol content of beer, $10 \%$ for wine, $19 \%$ for fortified wine, $45 \%$ for home made liquor, $40 \%$ for vodka, and $20 \%$ for other alcohol. As to the possible doubts on the validity of self-reported measures of alcohol consumption, we follow the idea, again found in Baltagi and Geishecker (2006), that selfdeclared alcohol consumption in Russia should not be severely under-reported, since there is less social stigma attached to alcohol consumption with respect to other countries. While there is evidence of under-reporting alcohol consumption in the RLMS (Stillman, 2006), especially before an additional clarifying question was included in the survey (wave XV), this should not be an issue as far as under-reporting is randomly/uniformly distributed within each wave. Indeed, the identification of the coefficients of parental alcohol consumption in model (1) comes from cross-sectional variation. The reported evidence of a different level of under-reporting for men and women, should not be an issue as well, as we control separately for mother and father consumption.

Mother's and father's total grams of alcohol consumption during 1994-2001 are included in all the specifications of models (1) in levels as a time invariant variable within the set $a l c_{i} .{ }^{11}$ As suggested by the analysis of Figure $2,{ }^{12}$ to capture the slight non-linearities of the relationship between parental alcohol consumption and educational outcomes and the possible effect of nonparticipation we add also the squared value of mother and father total grams of alcohol and a dummy indicating a non-zero consumption.

The figures presented in Table 1 confirm that alcohol in Russia is mainly a male phenomenon. Drinking fathers drank on average 29.6 grams of alcohol per day (that corresponds to almost 2 standard glasses of vodka, each of which contains 15.57 grams of pure alcohol) and while mothers only 5.3 grams.

Contemporaneous alcohol consumption of the adult child is excluded from the main regressions, because of the further potential endogeneity issues. ${ }^{13}$. Instead, child alcohol consumption

\footnotetext{
${ }^{11}$ Because the sample selection includes adult children that were living with at least one parent in the period 1994-2001, a non negligible proportion of individuals had either the father or the mother absent in that period. While this implies that his/her alcohol consumption measure is missing, we set it to zero under the hypothesis that those children were not exposed. A robustness analysis conducted only with children with both parents present substantially confirms the results, with even larger coefficients, but the sample would have had a further source of possible selection bias.

${ }^{12}$ The figure plots the results of a semiparametric regression (Robinson, 1988; Verardi and Debarsy, 2012) of parental alcohol consumption on educational outcomes once controlling for all confounders in model (1), i.e. par ${ }_{i}$, $a d u_{i t}$ and $g_{e} o_{i}$.

${ }^{13}$ Although a robustness analysis conducted including also contemporaneous alcohol consumption produces nearly identical results. The potential reverse causality bias is likely to mostly harm the estimation of the contemporaneous alcohol consumption coefficient, while other coefficients (especially those that are time invariant) are less affected. While current alcohol consumption levels are not included in the regressions, it is still interesting to verify that
} 
Figure 2: Semiparametric regressions of the outcomes on parental alcohol consumption.

Mother total grams of alcohol per day
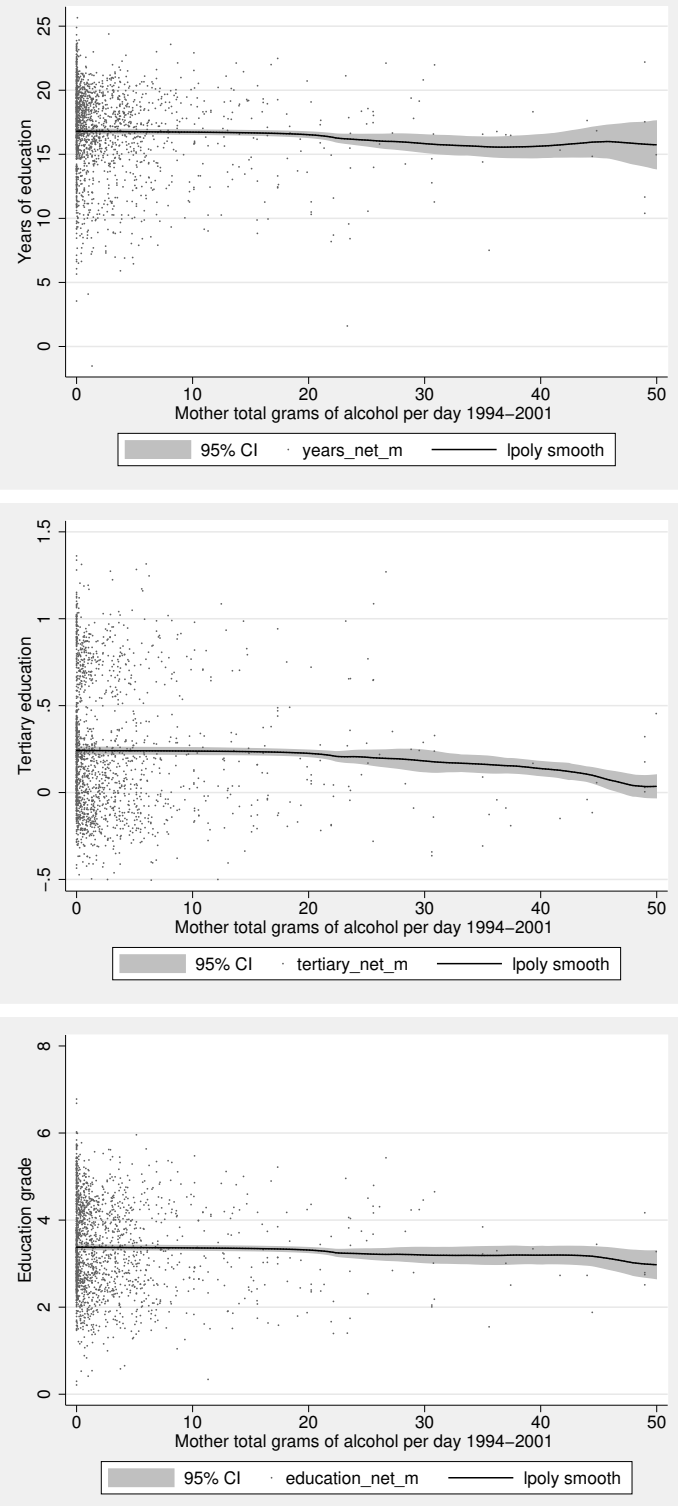

Father total grams of alcohol per day
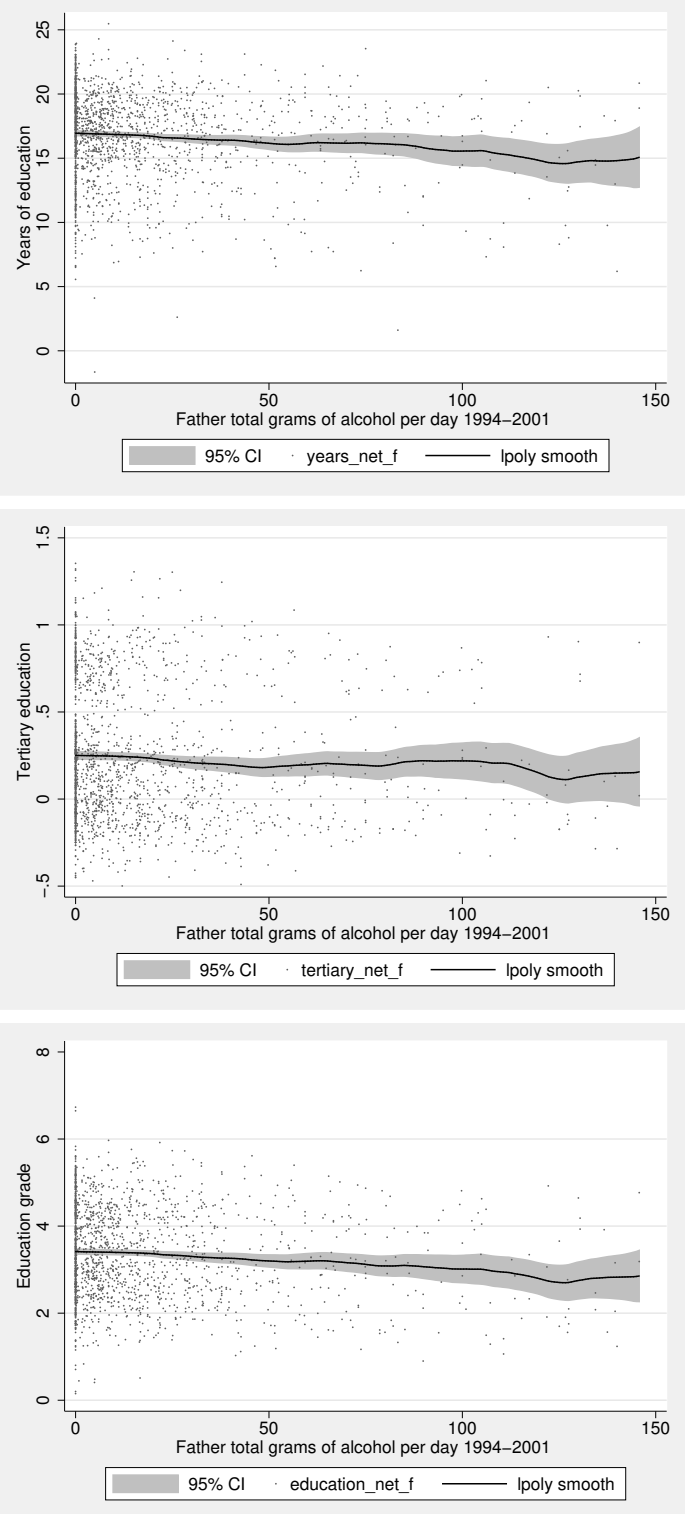
during adolescence (14-17 years old) is used as a possible mediator of the negative effects of parental drinking on the long run educational attainment of their children. ${ }^{14}$ The offspring alcohol consumption during adolescence is actually not so moderate (for drinkers 8.5 grams of alcohol per day on average) but significantly smaller comparing with their parents, in line with the evidence that in Russia drinking habits are stronger among older individuals (Herzfeld et al., 2014). The gender composition is maintained, with girls drinking 4.1 grams per day, and boys 12.5 grams. While on average girls drink only about $20 \%$ less than their mothers, boys drink less than half the amount of alcohol of their fathers', but still more than two times their mothers' consumption.

The other mediator that we include and is directly linked with alcohol consumption is a dummy indicating whether the mother was drinking during younger siblings pregnancies (about $1.2 \%$ in our sample). Even if we cannot observe mother's drinking when the adult children were foetus and directly test for the in-utero effects of alcohol consumption, we can reasonably assume that a mother's behaviour is likely to be consistent along successive pregnancies and use this variable as a proxy for the in-utero effects of alcohol consumption. To construct this variable we use information about mothers' alcohol consumption and whether she was pregnant or not at the time of the interview. This excludes the cases of mothers drinking during the first months of unexpected pregnancies, which may result in an further underestimation of the mediation power of this variable.

\subsection{Mediators}

The choice of variables for the mediation analysis is somewhat complicated by the need to comply with the sequential ignorability assumption (see Section 2.2). In this respect, the adopted strategy is that variables are built to respect the treatment-mediator-outcome time sequence in line with the sequental ignorability assumption. Thus, the treatment, i.e. parental alcohol consumption during childhood, is recorded in years 1994-2001, the mediators (except bad health during childhood and mother drank during other pregnancies) are computed for the period 2002-2004, and the outcomes in 2005-2014. This allows to exclude at least reverse causality issues, while for the treatment a formal analysis of potential endogeneity issues is conducted.

The first pathway that may determine adverse child outcomes is through a larger probability of children of alcoholics of developing drinking problems. The literature suggests that genetics may play an important role in this respect (see, for example Jennison and Johnson, 1998). Indeed, drinking at high school and college has been negatively related to educational attainment (Williams et al., 2003; Chatterji, 2006; Koch and McGeary, 2005; Balsa et al., 2011). To analyse for this transmission mechanism, the variable used is alcohol consumption of the child during adolescence, already described earlier is Section 3.3.

A second possible channel is identified in the adverse effects of parental problem-drinking on a

the conditional average consumption is about 10.4 grams per day, 4.9 for women and 14.8 for men. It seems that daughters when adult catch up almost $100 \%$ of their mothers consumption, while sons only reach about half of their fathers consumption.

${ }^{14}$ See Section 3.4 for an Exhaustive discussion of all mediators. 
child's health. For example Balsa and French (2012) find that parental drinking increases the use of acute health care services by children (mental health services and hospitalization). Hanć et al. (2015) found that children growing up in families with alcohol addicted parents are characterized by lower body height and BMI, and are included in the groups of risk of underweight. As a proxy for this channel, the chosen variable is the frequency of having had health problems during childhood (1994-2001), with an average of 0.29 over a minimum of 0 (never had health problems in the month preceding the interview) and a maximum of 1 (always, i.e. whenever interviewed).

Alcoholism can be also associated with reduced family cohesion, increased probability of singleparent household, and poor supervision of children. To analyse this aspect we include a dummy variable indicating whether the parents have divorced in the period 2002-2004 (thus after the parental alcohol consumption window chosen, but before adulthood), which is the case for about $5.6 \%$ of the sample.

A more direct negative effect of parental problem-drinking on adult children outcomes is that the child may need to subtract time from schooling or work for assisting parents with health problems related with their drinking habits. In this respect, the variable included is whether the child had to help their parents during adolescence (14-17 years old), which is the case for $3.6 \%$ of the sample.

A last channel is through prenatal exposure to alcohol. The medical literature since Jones and Smith (1973) has found that foetuses exposure to excessive alcohol doses (Foetal Alcohol Syndrome) are likely to have devastating effects on development (Mattson and Riley, 1998). FAS has been associated with structural abnormalities, growth deficit and neuro-behavioural anomalies, which can result in deficiencies in activity, attention, learning, memory, language, motor and visuo-spatial abilities. Nevertheless, even smaller amounts of alcohol can produce part some of the symptoms, and may still have consequences for the child educational attainment. ${ }^{15}$ For example, recently Nilsson (2017) has shown that drinking during pregnancy has cost for educational and labour market outcomes of the children. Because our panel is not sufficiently long to directly observe mothers' drinking behaviour during the same child pregnancy, as a proxy we use a dummy for whether the mother drank while pregnant of a sibling (see, Section 3.3 for more details).

\subsection{Other variables}

The other variables included in the regressions include father's and mother's characteristics in the period 1994-2001, including their average wage rate and work status (i.e. being working or on leave), ${ }^{16}$ whether they have a university degree, whether they were absent, their nationality and their age at birth. In addition we included the number of other children living in the household (including but not limiting to siblings), and whether the household lived mostly in a rural settle-

\footnotetext{
${ }^{15}$ This lighter condition is referred to as Fetal Alcohol Spectrum Disorders (FASDs).

${ }^{16}$ In the case of work status, the variable takes 1 if the mother/father has been employed during all the period and 0 if it has been always unemployed. Intermediate values represent the proportion of waves where the father/mother has been employed over total number of waves in which they were interviewed.
} 
ment in the period. What is worth noting here is that for many individuals (21\% of the sample) the father was absent. This is a fairly large proportion that includes cases of migration, family split and death, all happened before the first available observation of the household. On the other hand, only $1.7 \%$ of mothers were absent during childhood. ${ }^{17}$ About $4 \%$ of children had either non-Russian father or mother, while on average they had slightly more than one other child living in the household (mostly siblings). $25.8 \%$ of children lived mostly in a rural settlement during childhood.

Adult child contemporaneous variables include age, already described in Section 3.1, age at round X (2001), whether the child is older than 22 (age at which one would be expected to obtain a university degree), sex (being male), cohabiting, being married, the number of children, whether he/she suffers a chronic illness, whether he/she has Russian nationality, and the macro-region of residence. Notably, the sample is very gender balanced, with very few individuals cohabiting (just about $2 \%$ ), but with a relevant proportion of married (23\%), despite the relatively young age. The average number of children is, as expected, quite low, while more than $26 \%$ of them suffer a chronic illness (which includes some increasingly common illnesses such as allergies and diabetes, but also several other less frequent ones).

\section{Results and discussion}

This section presents and discusses the results of the estimation of the impact of parental drinking during childhood on the long run educational attainment of children, the corresponding robustness tests, and a formal mediation analysis of the most likely transmission mechanisms.

\subsection{Parental alcohol consumption and children's educational attainment}

Table 4 reports the marginal effects of mother's and father's total grams of alcohol consumed per day during childhood on the long run educational outcomes. ${ }^{18}$ The results are presented for the full sample and separately for males and females children and with an increasing set of regressors from model 1 to model 4 .

The first thing to notice is that the marginal effects are very consistent to adding additional regressors for all outcomes when including additional sets of regressors. While this does not rule out endogeneity issues, which is discussed in more details in the next subsection, it is at least a good sign of robust estimates.

Perhaps the most relevant result is that what is impacting the most long run educational outcomes is mother's drinking, rather than father's. For the full sample, one additional gram of

\footnotetext{
${ }^{17}$ To avoid loosing many observation and introducing a further source of selection bias, when a parent is absent all of his/her specific variables are set to zero. A robustness analysis conducted only with children with both parents present substantially confirms the results, with even larger coefficients.

${ }^{18}$ Full estimation tables of models (1) are presented in the Online Appendix, except Table 5, which shows the results for years of education for the full sample to give a general overview of the impact of the other variables on the outcomes.
} 


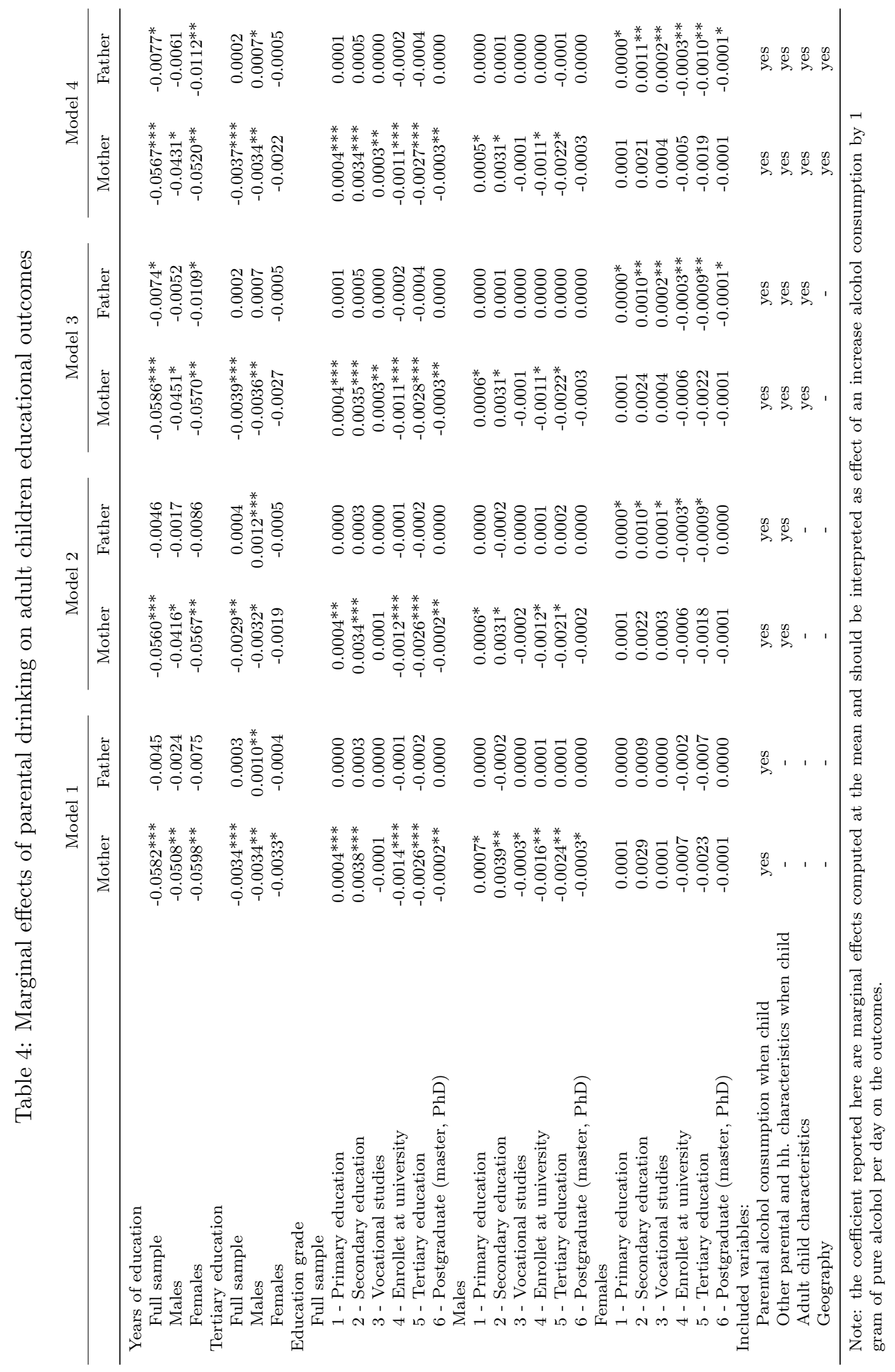


pure alcohol per day drank by the mother during childhood causes education years to reduce by about 0.057 . In Russia, a standard glass of vodka (50ml) contains about 15.57 grams of alcohol, which means that an additional glass of vodka per day would reduce schooling by almost one year (0.882), quite a huge impact.

Table 5, however, detailing the coefficients of all alcohol variables reveals a more complex relationship, with a positive effect of the indicator for mother drinking (of about 0.655 years) and a negative marginal effect of additional grams of alcohol which is decreasing in magnitude. This means that for moderate drinkers the overall effect can be positive. For example, the average drinking mother drank about 5.3 grams per day, and the total effect of her alcohol consumption on her child years of education is an increase by 0.35 years. The effect of mother drinking turns negative at about 12 grams per day, and one glass of vodka per day produces a reduction of 0.171 years of education respect to children of abstemious mothers. The largest impact can be found at 60.8 grams (about 4 glasses of vokda per day) and amounts to -1.19 years of education.

Father's drinking impact is only significant at $10 \%$ and much smaller, about 0.12 years, or one month and a half, for an additional glass of vodka.

Although estimates for the males and females sub-samples show lower significance levels (mostly because of the reduced sample size), the magnitude of the marginal effects are similar, and slightly larger for females.

The impact of parental drinking during childhood on the probability of achieving a tertiary education degree show a similar pattern. An additional gram drank by the mother reduces the probability by 0.37 percentage points, or $1.7 \%$, while drinking one more vodka reduces it by 5.8 percentage points, or about $27 \%$. Father's alcohol consumption has no significant impact on the probability of having tertiary education, and the impact of mother's consumption is significant only for males (see Table 4).

As to education grade, one additional gram of alcohol consumed by the mother increases the probability of low education (especially secondary education, by 0.34 percentage points) and decreases the probability of both being enrolled at university (by 0.11 and 0.27 percentage point respectively). The results disaggregated by gender suffer more from the sample size reduction here, showing no significant impact of mother's alcohol consumption on daughters, while father's consumption is significant despite the smaller magnitudes of the marginal effects. For sons, the reverse is true, father's consumption is not significant, and with very small marginal effects.

The impact of the other variables included in model (1) is shown in Table 5 only for years of education in the full sample, in order to give a general sense of their effects on the educational outcomes, which is very similar.

Among parents variables during childhood, the most important are both parent's education and father's work status and wage rate, all of which have a positive impact, while the number of siblings is associated with lower educational achievements. Interestingly, parental absence is not significantly associated with lower educational achievements. As to the adult child characteristics, age is clearly an important factor, but the cohort of birth shows no trends. As expected, 


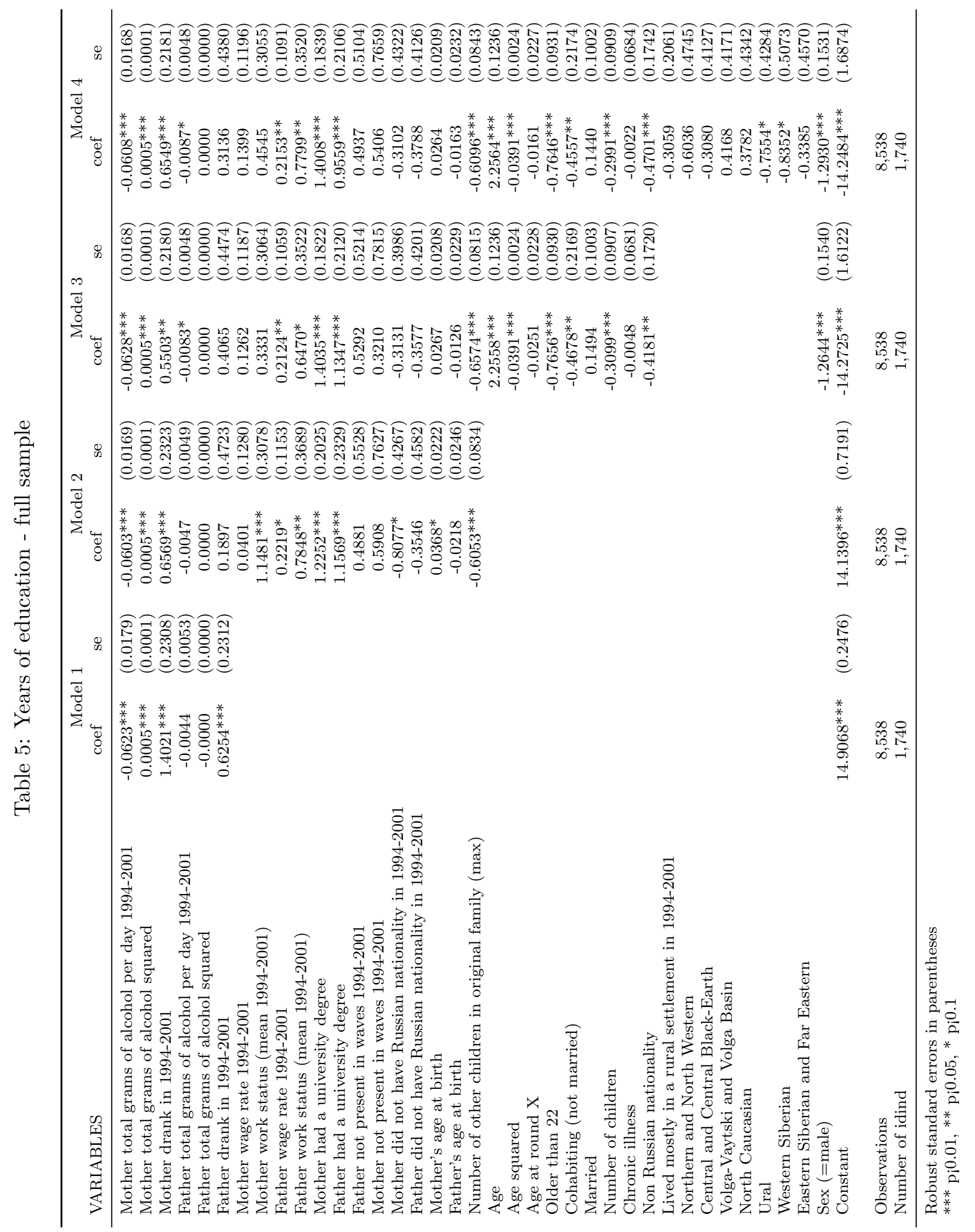


Table 6: Robustness to potential endogeneity

\begin{tabular}{ccccccccc}
\hline & \multicolumn{2}{c}{ Main } & \multicolumn{2}{c}{ Lewbel } & \multicolumn{2}{c}{ Mundlak } & \multicolumn{2}{c}{ Hausman-Taylor } \\
& Parameter & s.e. & Parameter & s.e. & Parameter & s.e. & Parameter & s.e. \\
\hline Years of education & & & & & & & & \\
$\quad$ Mother grams of alcohol & $-0.0608^{* * *}$ & $(0.0168)$ & $-0.0548^{* * *}$ & $(0.0215)$ & $-0.0565^{* * *}$ & $(0.0162)$ & $-0.5348^{*}$ & $(0.3129)$ \\
$\quad$ Father grams of alcohol & $-0.0087^{*}$ & $(0.0048)$ & -0.0080 & $(0.0053)$ & -0.0057 & $(0.0046)$ & -0.0322 & $(0.0667)$ \\
Tertiary education & & & & & & & & \\
$\quad$ Mother grams of alcohol & $-0.0032^{* *}$ & $(0.0014)$ & $-0.0048^{* *}$ & $(0.0020)$ & $-0.0029^{* *}$ & $(0.0014)$ & -0.0254 & $(0.0185)$ \\
$\quad$ Father grams of alcohol & 0.0002 & $(0.0004)$ & 0.0002 & $(0.0005)$ & 0.0003 & $(0.0004)$ & -0.0003 & $(0.0041)$ \\
Education grade & & & & & & & & \\
$\quad$ Mother grams of alcohol & $-0.0120^{* * *}$ & $(0.0044)$ & $-0.0120^{*}$ & $(0.0062)$ & $-0.0105^{* *}$ & $(0.0043)$ & $-0.1423^{*}$ & $(0.0825)$ \\
$\quad$ Father grams of alcohol & -0.0020 & $(0.0013)$ & -0.0017 & $(0.0014)$ & -0.0013 & $(0.0012)$ & 0.0031 & $(0.0177)$ \\
\hline
\end{tabular}

Notes: Lewbel's and Hausman-Taylor estimatore are developed only as linear estimators, thus the corresponding coefficients would not be directly compared to those of the Probit and Ordered Probit. Thus, to report comparable coefficients, the main regressions for teritary education and education grade have been re-estimated as linear RE regressions.

girls have better outcomes, while cohabiting, the number of children and being non-Russian all impact negatively on years of education. Chronic illnesses and being married are not important determinants of educational outcomes. Finally geographical variables have little impact on years of education.

Looking at gender specific results (the corresponding full tables can be found on the Online Appendix), we find that being cohabiting has a negative impact only for males, while the number of children and being non-Russian only hampers female education.

As to possible endogeneity issues, the coefficients of parental alcohol consumption obtained in the main regressions (model 4) are compared with the estimators proposed by Lewbel (2012), Mundlak (1978) and Hausman and Taylor (1981). Because both Lewbel's and Hausman-Taylor's estimators are developed only for the linear model, the estimates for tertiary education and education grade are re-estimates as linear RE regressions for the robustness analysis. In this way all coefficients are directly comparable.

Table 6 reports the coefficients of Mother's and Fathers total grams of alcohol per day in 1994-2001. ${ }^{19}$ A first look reveals that the sign and significance of mother's alcohol consumption is confirmed in basically all estimations (except the Hausman-Taylor for tertiary education), while the coefficient of father's alcohol consumption that was significant at $10 \%$ in the main regression, loses significance in all other specifications.

Looking more closely at the values of the coefficients estimates, it can be seen that they are very close to the main regression both for Lewbel's and Mundlak's estimators. The HausmanTaylor result, instead is different by an order of magnitude. It is worth noting that this estimator was rather sensitive to which variables were declared exogenous. We would thus stress the good results obtained with the estimator proposed by Lewbel (2012), which despite the supposedly reduced efficiency, produces very similar coefficients that are robust to endogeneity.

\footnotetext{
${ }^{19}$ Although only these coefficients are shown in Table 6, the robustness is conducted for the full regressions, considering all parental alcohol variables as endogenous. Full tables are available in the Online Appendix.
} 
Table 7: Mediation analysis

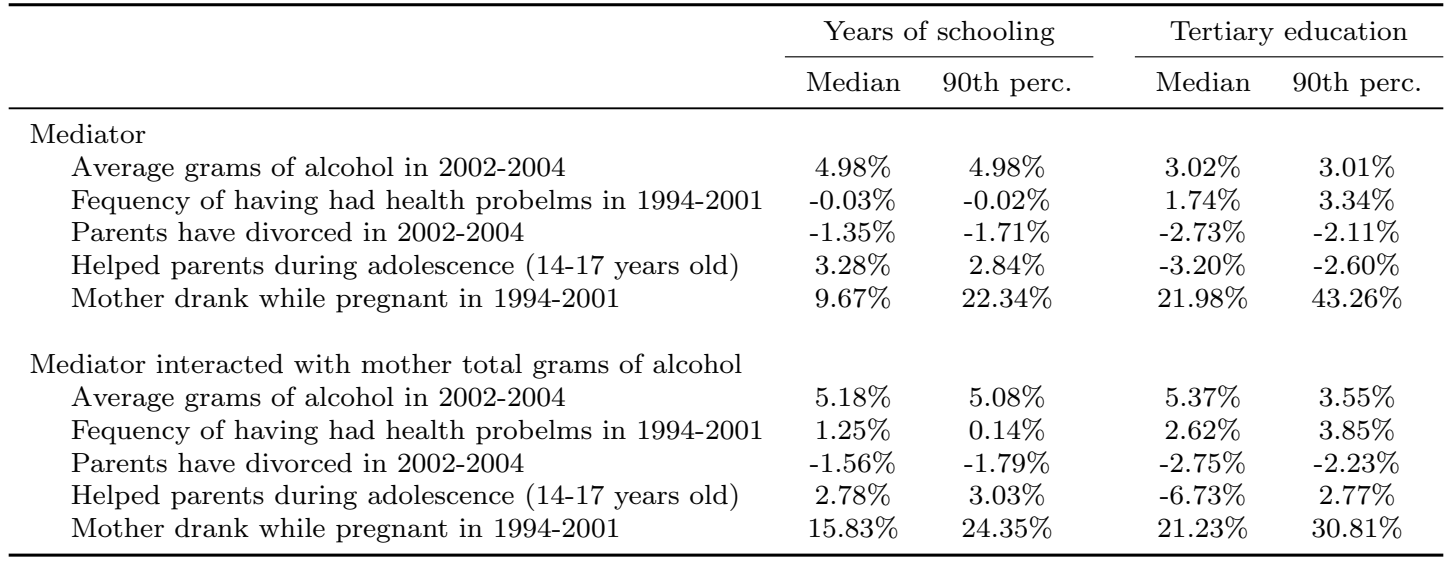

These results suggest a consistent estimation of the mother's alcohol consumption negative and significant impact on her children long run educational attainment, confirming that the main findings are robust to alternative model specifications and estimations methods.

\subsection{Transmission mechanisms}

Thanks to the methodology developed by Imai et al. (2010) and Hicks et al. (2011), and thanks to the richness of the RLMS data, it has been possible to analyse the transmission mechanisms that make maternal alcohol consumption negative for the long run educational attainment of her children. Because the methodology is not yet developed for categorical outcomes, we focus here on years of education and tertiary education only.

The proposed mediation analysis has two peculiarities. First, while the typical mediation analysis disentangles the transmission mechanisms of a binary treatment, mother's alcohol consumption is a continuous variable. It is still possible to conduct a mediation analysis but it is required to define a level of the continuous variable for which the treatment is triggered. We have chosen two different values, the conditional median of mothers alcohol consumption distribution and the 90th percentile. In this way the treatment definition is meant to exclude moderate drinkers for the median, and to only account for problem drinkers for the 90th percentile.

In addition, we allow for the interaction between the treatment and the mediator in the outcome equation. While standard mediation analysis assumes no interaction between treatment and mediators, it has be often recognized as an unrealistic assumption (Imai et al., 2010).

Table 7 reports the results of the mediation analysis. The first half assuming no interaction between treatment and mediators, the second half relaxing this assumption. Because the results are significantly different, in the comments we will refer only to the second half of the table, which is realized under less restrictive assumptions.

The genetic channel of transmission is accounted for by including as a mediator total grams 
of pure alcohol per day consumed by the child during adolescence (14-17 years old), that is after the observed childhood period but before adulthood. Looking at the results, the genetic channel seems to play little role in transmitting the negative effects of mother drinking during childhood, just about $5 \%$ of the total effect, both for years of schooling and tertiary education. Additional analysis reveals that in our sample there is little evidence that parents alcohol consumption is significantly correlated with the adolescent and adult child alcohol consumption. The correlation of adolescents' alcohol consumption with their parents, just $6.7 \%$ and $2.8 \%$, with mother's and father's consumption respectively. For the adult child correlations are even smaller, $3.7 \%$ and $2.2 \%$ respectively. This limited evidence, however, is not sufficient alone to discard the genetic transmission channel for other more long term outcomes, such as life-cycle wages, because genetic predispositions may lead to alcoholism or problem-drinking at later ages.

The second channel of transmission identified by the literature acts through child health issues, and it is controlled for through a variable indicating the frequency with which the child had health problems in 1994-2001. Child health issues seem to play a marginal role as transmission mechanism of parental drinking on their long run educational outcomes, ranging from $0.14 \%$ to $3.85 \%$. Another indicator of negative circumstances that may arise as a consequence of parental alcohol consumption, is family disruption. Parental divorce in 2002-2004 is found to have no role as a mediator for parental drinking. Indeed, although the percentages of mediations are very small, just about 1-2\%, their sign is negative, indicating that if any divorce reduces the negative effects of parental drinking, probably through lower exposure in the successive years. Divorce is indeed found to be negatively and significantly associated with both years of education and tertiary education, but not as a transmission mechanism for parental drinking.

A third channel, identified by the time spent in helping parents in bad health possibly because of the consequences of past excessive alcohol consumption, is controlled by a dummy indicating that the child helped parents during adolescence. This variable turns out to be a very weak mediator of parental drinking, just about 2-3\% of the effect of parental alcohol consumption. It is worth noting, however, that it was not possible to check whether parents needed help because of alcohol-related health issues or for other reasons.

Finally, the last channel of transmission identified by the literature, that of foetus exposure to excessive amounts of alcohol (Fetal Alcohol Syndrome) cannot be directly tested because the duration of the longitudinal study is not sufficient to follow an individual from conception to the graduation age. However, it was possible to observe whether the mother was pregnant of a sibling and drinking while pregnant. It seems reasonable to assume that the mother may have had the same behaviour in previous pregnancies, including that of the observed individual. The results suggest it to be the most relevant transmission mechanism through which maternal drinking negatively affects long run educational outcomes, with a proportion of mediator that spans from $15.8 \%$ to $30.8 \%$ depending on the outcome and level chosen for the treatment. It is worth noting that drinking during pregnancy was relatively common in the sample under analysis as about $26 \%$ of pregnant women did consume alcohol in 1994-2001. These findings are in line with recent 
evidence reported by Nilsson (2017) for Sweden.

In addition, the mediated impact increases substantially with the amount of alcohol consumed by the mother, suggesting that a threshold effect is probably at work. In fact about $4.5 \%$ of pregnant drinkers in 1994-2001 drank at least one alcohol unit per day (8 grams of pure alcohol) and among them, the average consumption is 50.3 grams of pure alcohol, ${ }^{20}$ indicating that about $5 \%$ of pregnancies were at risk of FAS in waves 1994-2001. As a final note, it is important to recognize that mothers drinking behaviour is still far from ideal in recent years, with about $10.8 \%$ of pregnant women declaring to have consumed alcohol in the month preceding the interview in 2014.

Remarkably, even taking all the mediators analysed together, it is possible to explain only about 30-35\% of the negative effect of maternal alcohol consumption on long run educational achievement of the child. Assuming that parental alcohol consumption per se should not have negative consequences, the unexplained part may be due either by the quality of variables chosen as proxies of the transmission mechanisms or by some other mechanisms that could not be tested because a proxy was not available in the data. Further investigations in this sense are left for future research.

\section{Conclusions}

This study analyses the potential impact of parental problem-drinking behaviour on adult child educational attainment using 19 waves of the Russian Longitudinal Monitoring Survey. The observation of children throughout their adulthood and the availability of a wide set of past and contemporary individual characteristics of the child and his/her parents, allow us to find significant intergenerational costs of parental problem-drinking in terms of human capital development, which are likely to have further implications also for future labour market opportunities and income mobility. In particular an excessive alcohol consumption by the mother during childhood is consistently associated less years of education, a lower level of education achieved and a lower probability of having an university degree for the children when adult. Fathers drinking is only weakly negatively associated with years of education. These results are robust to the possible endogeneity arising from the correlation of parental drinking variable with the random individual specific effect.

Thanks to the unique characteristics of the data used, such as the direct quantitative measures of parental drinking, together with numerous parental and children characteristics, it is possible to explore the mechanisms of transmission of parental problem-drinking to long term children outcomes. Of the four main transmission mechanisms suggested by the literature (genetics, child health/familiar issues, parental caring, and pregnant drinking), we find a significant role for excessive prenatal exposure to alcohol and, to a lesser extent, intergenerational transmission of drinking habits. However, even accounting for all mediators together, it is possible to explain only

\footnotetext{
${ }^{20}$ We excluded from calculation a clear outlier who declared to drink 1300 grams of pure alcohol per day.
} 
about $30-35 \%$ of the negative effect of maternal alcohol consumption on the long run educational achievement of the child. Assuming that parental alcohol consumption per se should not have negative consequences on children outcomes, this finding calls for further research on this aspect.

Traditionally the economic consequences and social costs of problem drinking focus on direct costs, such as health care costs, productivity reduction and criminality, there is a growing body of literature suggesting that the impact of excessive alcohol consumption on other family members is a relevant issue, both in terms of welfare losses (Menon et al., 2017; Giannelli et al., 2013) and in terms of offspring future productivity (Balsa, 2008; Nilsson, 2017). The present study adds further evidence on this respect, highlighting a relationship between parental drinking and lower long-term educational achievements of children. It is increasingly clear that excessive alcohol consumption generate households negative externalities that imply short and long-term social costs that should not be ignored when evaluating policy interventions. This also suggest that programs aimed at supporting alcoholics in their attempts to recovery should be targeted to the whole family rather than the individual, with a special attention for children. 


\section{References}

Ajilore, O., A. Amialchuk, and K. Egan (2016). Alcohol consumption by youth: Peers, parents, or prices? Economics \& Human Biology 23, 76-83. 2, 6

Balsa, A. I. (2008). Parental problem-drinking and adult childrens labor market outcomes. Journal of Human Resources 43(2), 454-486. 2, 3, 4, 6, 25

Balsa, A. I. and M. T. French (2012). The impact of parental drinking on children's use of health care. Substance Use \& Misuse 47(4), 450-460. 2, 16

Balsa, A. I., L. M. Giuliano, and M. T. French (2011). The effects of alcohol use on academic achievement in high school. Economics of Education Review 30(1), 1-15. 2, 15

Baltagi, B. H. and I. Geishecker (2006). Rational alcohol addiction: evidence from the Russian longitudinal monitoring survey. Health Economics 15(9), 893-914. 3, 13

Barber, J. G. and R. Gilbertson (1999). The drinker's children. Substance use 83 misuse 34(3), 383-402. 2

Baum, C. F., M. E. Schaffer, et al. (2017). Ivreg2h: Stata module to perform instrumental variables estimation using heteroskedasticity-based instruments. Statistical Software Components. 7

Böckerman, P., A. Hyytinen, and T. Maczulskij (2017). Alcohol consumption and long-term labor market outcomes. Health Economics 26(3), 275-291. 2

Brainerd, E. and D. M. Cutler (2005). Autopsy on an Empire: Understanding Mortality in Russia and the Former Soviet Union. The Journal of Economic Perspectives 19(1), 107-130. 3

Carrell, S. E., M. Hoekstra, and J. E. West (2011). Does drinking impair college performance? evidence from a regression discontinuity approach. Journal of Public Economics 95(1), 54-62. 2

Chatterji, P. (2006). Does alcohol use during high school affect educational attainment?: Evidence from the National Education Longitudinal Study. Economics of Education Review 25(5), 482497. 2,15

Chatterji, P., D. Dave, R. Kaestner, and S. Markowitz (2004). Alcohol abuse and suicide attempts among youth. Economics \& Human Biology 2(2), 159-180. 2

Chatterji, P. and S. Markowitz (2001). The impact of maternal alcohol and illicit drug use on childrens behavior problems: evidence from the children of the national longitudinal survey of youth. Journal of Health Economics 20(5), 703-731. 2 
Christoffersen, M. N. and K. Soothill (2003). The long-term consequences of parental alcohol abuse: a cohort study of children in denmark. Journal of substance abuse treatment 25(2), 107-116. 2, 3

Connell, A. M. and S. H. Goodman (2002). The association between psychopathology in fathers versus mothers and children's internalizing and externalizing behavior problems: a metaanalysis. Psychological bulletin 128(5), 746. 2, 4

Connolly, G., S. Casswell, J. Stewart, P. Silva, and M. O'Brien (1993). The effect of parents' alcohol problems on children's behaviour as reported by parents and by teachers. Addiction (Abingdon, England) 88(10), 1383-1390. 2

Cook, P. J. and M. J. Moore (1993). Drinking and schooling. Journal of Health Economics 12(4), 411-429. 2

Cuijpers, P., Y. Langendoen, and R. V. Bijl (1999). Psychiatric disorders in adult children of problem drinkers: prevalence, first onset and comparison with other risk factors. Addiction 94(10), 1489-1498. 2

Cunha, F., J. J. Heckman, and S. M. Schennach (2010). Estimating the technology of cognitive and noncognitive skill formation. Econometrica 78(3), 883-931. 4

Fertig, A. R. and T. Watson (2009). Minimum drinking age laws and infant health outcomes. Journal of Health Economics 28(3), 737-747. 2

Giannelli, G. C., L. Mangiavacchi, and L. Piccoli (2013). Do parents drink their childrens welfare? Intra-household allocation of time between market labour, domestic work and child care in Russia. IZA Journal of Labor \& Development 2(1), 1-23. 2, 25

Hanć, T., Z. Czapla, A. Szwed, M. Durda, A. Krotowska, and J. Cieślik (2015). Growth and nutritional status of children from dysfunctional families with alcohol addicted parents in poland. Economics \& Human Biology 18, 101-109. 2, 16

Hausman, J. A. and W. E. Taylor (1981). Panel data and unobservable individual effects. Econometrica: Journal of the Econometric Society, 1377-1398. 8, 21

Heckman, J., R. Pinto, and P. Savelyev (2013). Understanding the mechanisms through which an influential early childhood program boosted adult outcomes. The American economic review 103(6), 2052-2086. 4

Herzfeld, T., S. Huffman, and M. Rizov (2014). The dynamics of food, alcohol and cigarette consumption in russia during transition. Economics \&f Human Biology 13, 128-143. 3, 6, 15

Hicks, R., D. Tingley, et al. (2011). Causal mediation analysis. Stata Journal 11(4), 605. 8, 22 
Hussong, A., R. Wirth, M. Edwards, P. Curran, L. Chassin, and R. Zucker (2007). Externalizing symptoms among children of alcoholic parents: Entry points for an antisocial pathway to alcoholism. Journal of abnormal psychology 116(3), 529. 2

Hussong, A. M., R. A. Zucker, M. M. Wong, H. E. Fitzgerald, and L. I. Puttler (2005). Social competence in children of alcoholic parents over time. Developmental Psychology 41(5), 747. 2

Imai, K., L. Keele, and D. Tingley (2010). A general approach to causal mediation analysis. Psychological methods 15(4), 309. 8, 22

Imai, K., L. Keele, T. Yamamoto, et al. (2010). Identification, inference and sensitivity analysis for causal mediation effects. Statistical science 25(1), 51-71. 8, 22

Jennison, K. M. and K. A. Johnson (1998). Alcohol dependence in adult children of alcoholics: longitudinal evidence of early risk. Journal of Drug Education 28(1), 19-37. 15

Jones, K. and D. Smith (1973). Recognition of the fetal alcohol syndrome in early infancy. The Lancet 302(7836), 999-1001. 2, 16

Keller, P. S., E. M. Cummings, P. T. Davies, and P. M. Mitchell (2008). Longitudinal relations between parental drinking problems, family functioning, and child adjustment. Development and Psychopathology 20(1), 195-212. 2

Koch, S. F. and K. A. McGeary (2005). The effect of youth alcohol initiation on high school completion. Economic Inquiry 43(4), 750-765. 15

Leonard, K. E. and R. D. Eiden (2002). Cognitive functioning among infants of alcoholic fathers. Drug and alcohol dependence 67(2), 139-147. 2

Lewbel, A. (2012). Using heteroscedasticity to identify and estimate mismeasured and endogenous regressor models. Journal of Business \& Economic Statistics 30(1), 67-80. 4, 7, 21

Marshal, M. P., B. S. Molina, W. E. Pelham, and J. Cheong (2007). Attention-deficit hyperactivity disorder moderates the life stress pathway to alcohol problems in children of alcoholics. Alcoholism: Clinical and Experimental Research 31(4), 564-574. 2

Mattson, S. N. and E. P. Riley (1998). A review of the neurobehavioral deficits in children with fetal alcohol syndrome or prenatal exposure to alcohol. Alcoholism: Clinical and Experimental Research 22(2), 279-294. 2, 16

Menon, M., F. Perali, and L. Piccoli (2017). Collective consumption: an application to the passive drinking effect. Review of Economics of the Household Forthcoming. 2, 25

Mundlak, Y. (1978). On the pooling of time series and cross section data. Econometrica, 69-85. 7,21 
Nilsson, J. P. (2017). Alcohol availability, prenatal conditions, and long-term economic outcomes. Journal of Political Economy 125(4), 1149-1207. 2, 3, 4, 16, 24, 25

Poon, E., D. A. Ellis, H. E. Fitzgerald, and R. A. Zucker (2000). Intellectual, cognitive, and academic performance among sons of alcoholics during the early school years: Differences related to subtypes of familial alcoholism. Alcoholism: Clinical and Experimental Research 24(7), 1020-1027. 2

Renna, F. (2007). The economic cost of teen drinking: late graduation and lowered earnings. Health Economics 16(4), 407-419. 2

Renna, F. (2008). Teens alcohol consumption and schooling. Economics of Education Review 27(1), 69-78. 2

Robinson, P. M. (1988). Root-n-consistent semiparametric regression. Econometrica: Journal of the Econometric Society, 931-954. 13

Serec, M., I. ŠVAB, M. Kolšek, V. ŠVAB, D. Moesgen, and M. Klein (2012). Health-related lifestyle, physical and mental health in children of alcoholic parents. Drug and Alcohol Review 31(7), 861-870. 2

Snow Jones, A., D. J. Miller, and D. S. Salkever (1999). Parental use of alcohol and children's behavioural health: a household production analysis. Health Economics 8(8), 661-683. 2

Stillman, S. (2006). Health and nutrition in eastern europe and the former soviet union during the decade of transition: A review of the literature. Economics 85 Human Biology 4(1), 104-146. 13

Verardi, V. and N. Debarsy (2012). Robinson's square root of n consistent semiparametric regression estimator in stata. Stata Journal 12(4), 726-735. 13

Williams, J., L. M. Powell, and H. Wechsler (2003). Does alcohol consumption reduce human capital accumulation? evidence from the college alcohol study. Applied Economics 35(10), 1227-1239. 15

Zohoori, N., T. A. Mroz, B. Popkin, E. Glinskaya, M. Lokshin, D. Mancini, P. Kozyreva, M. Kosolapov, and M. Swafford (1998). Monitoring the economic transition in the russian federation and its implications for the demographic crisisthe russian longitudinal monitoring survey. World Development 26(11), 1977-1993. 3 
Online Appendix: Full Tables 


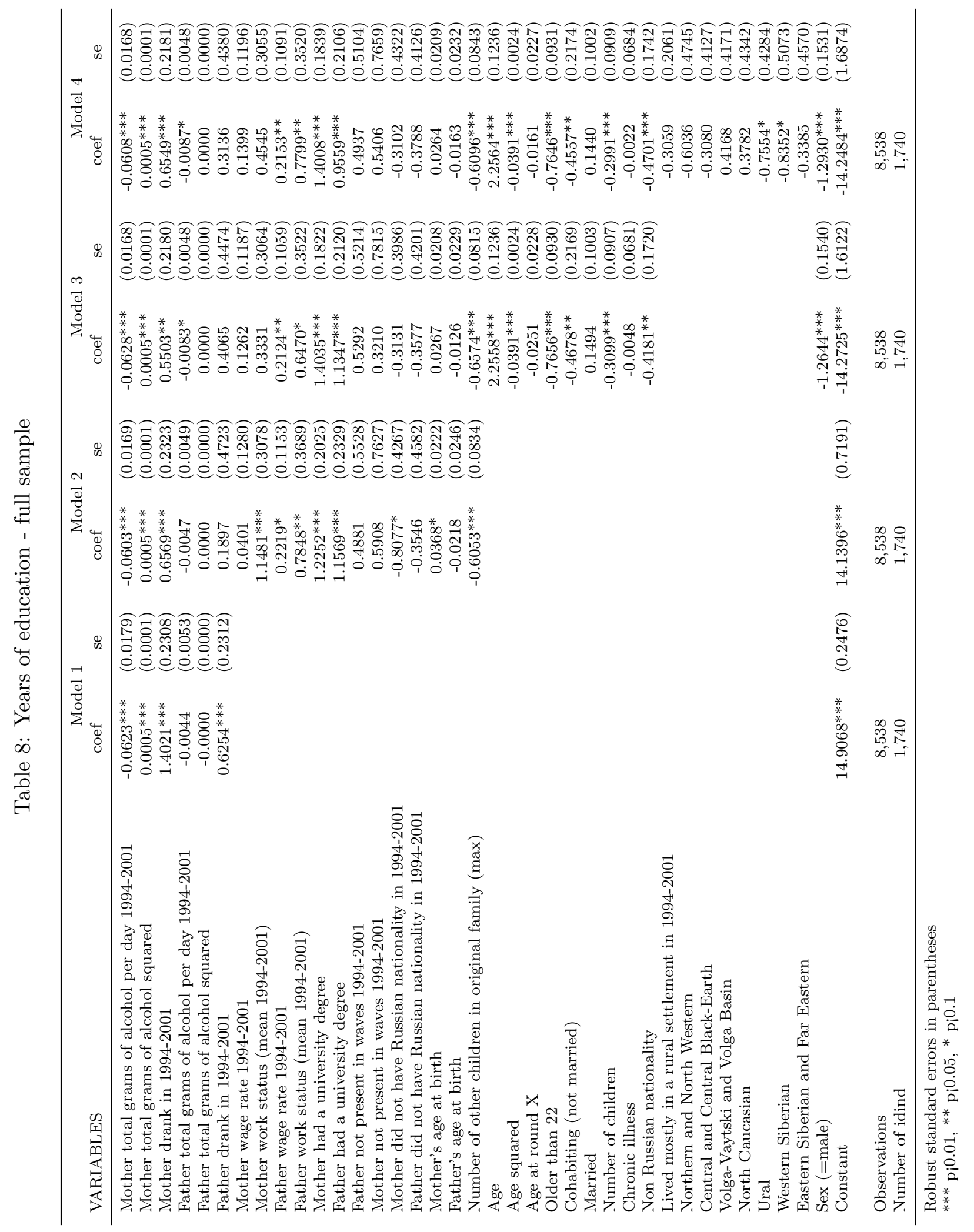




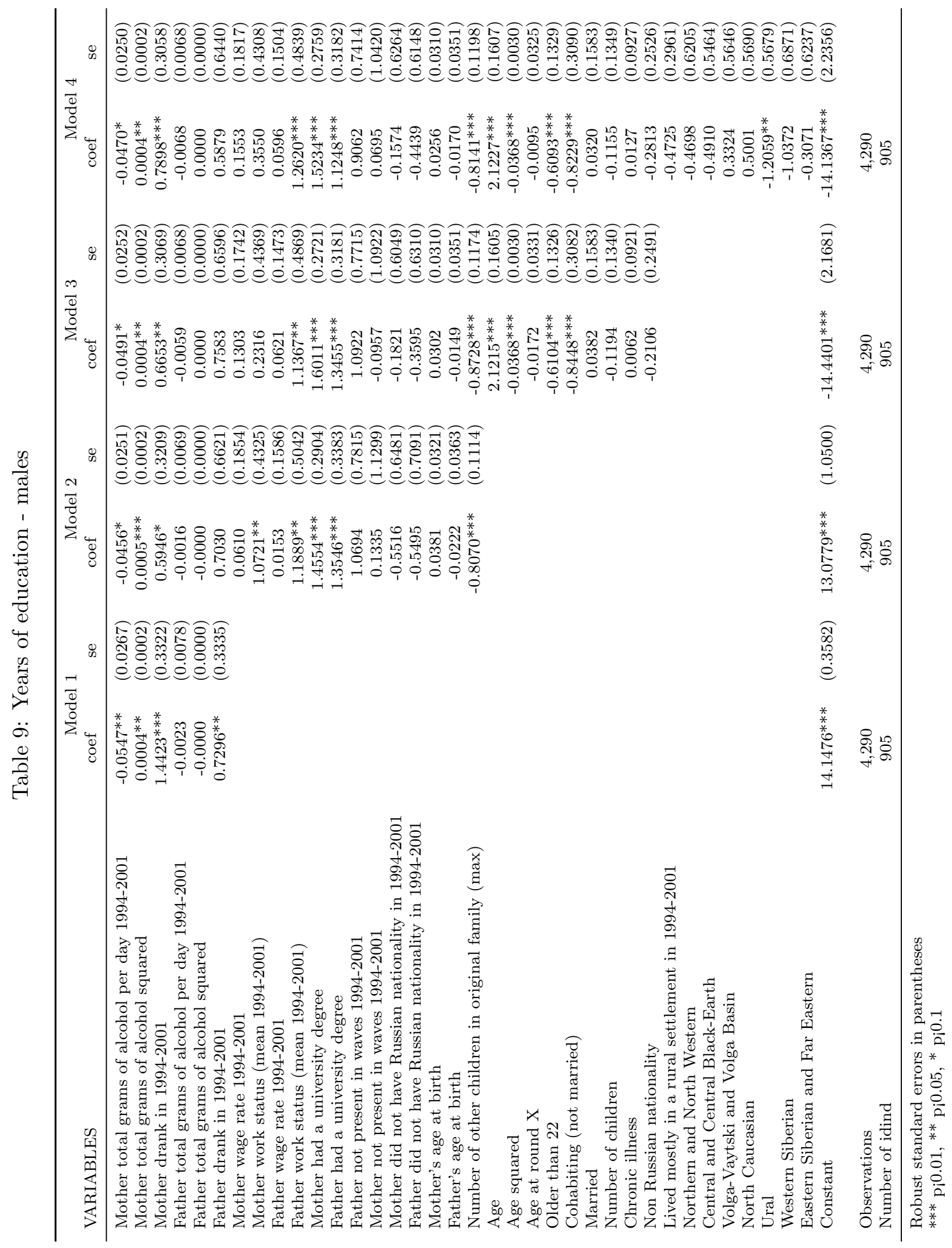




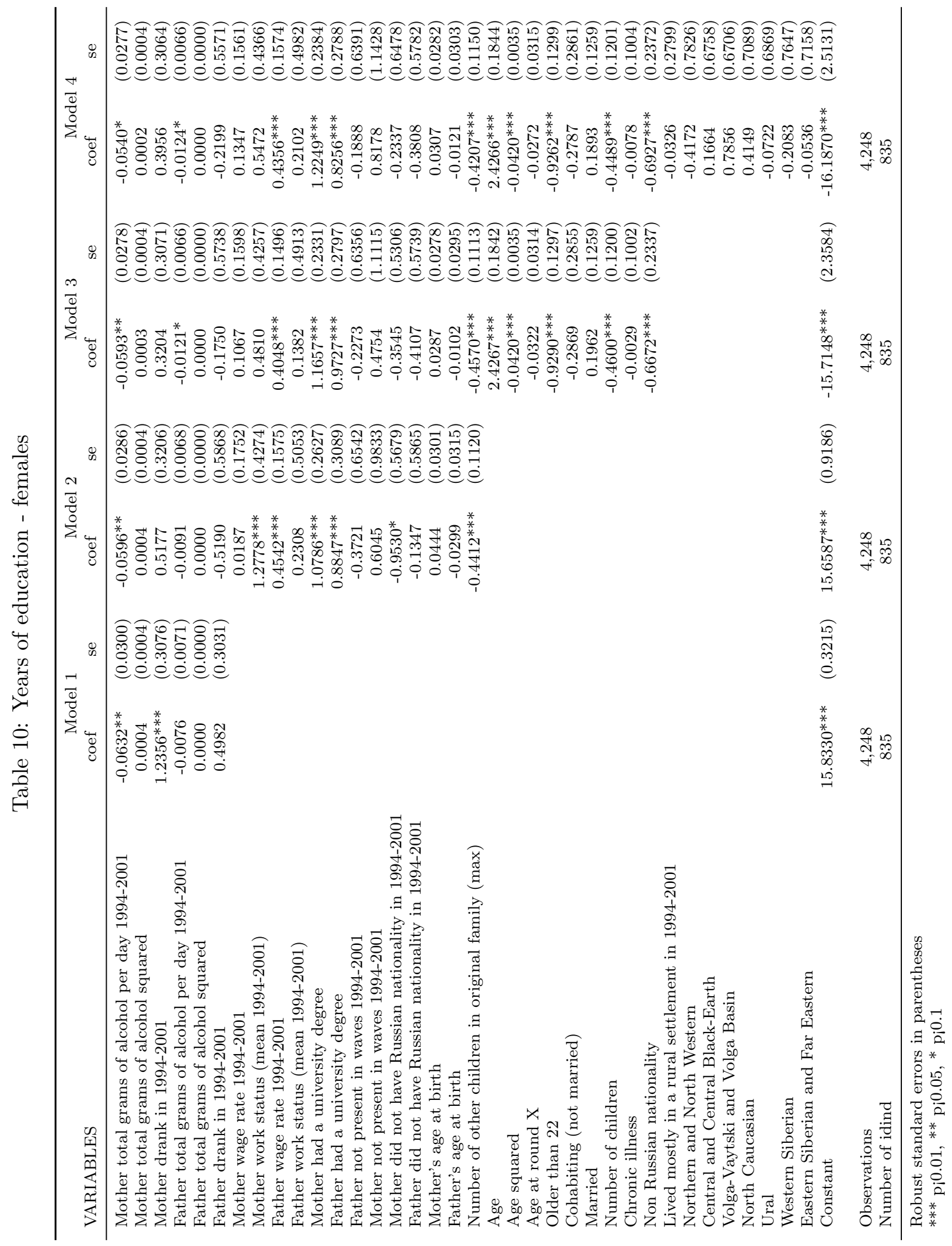




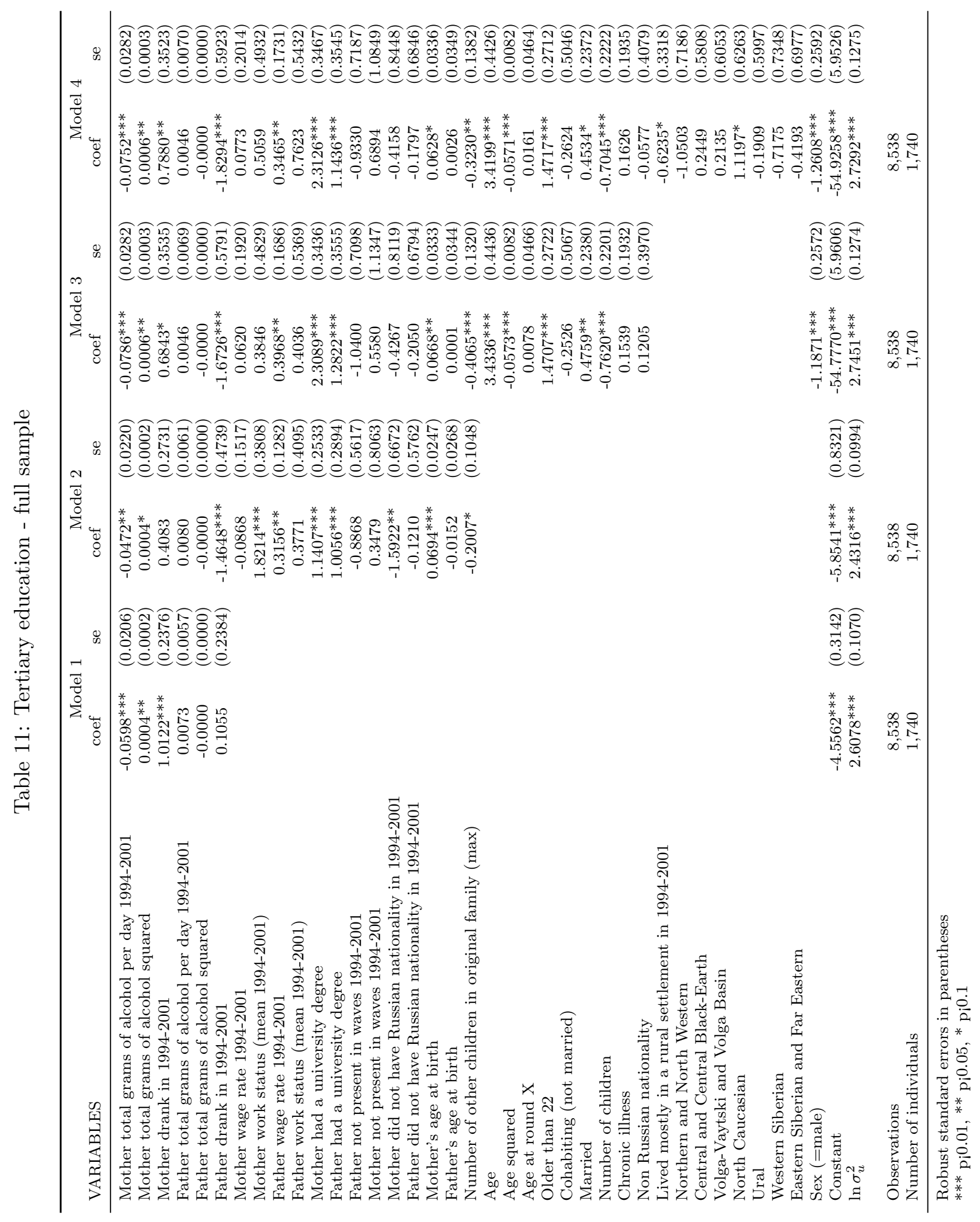




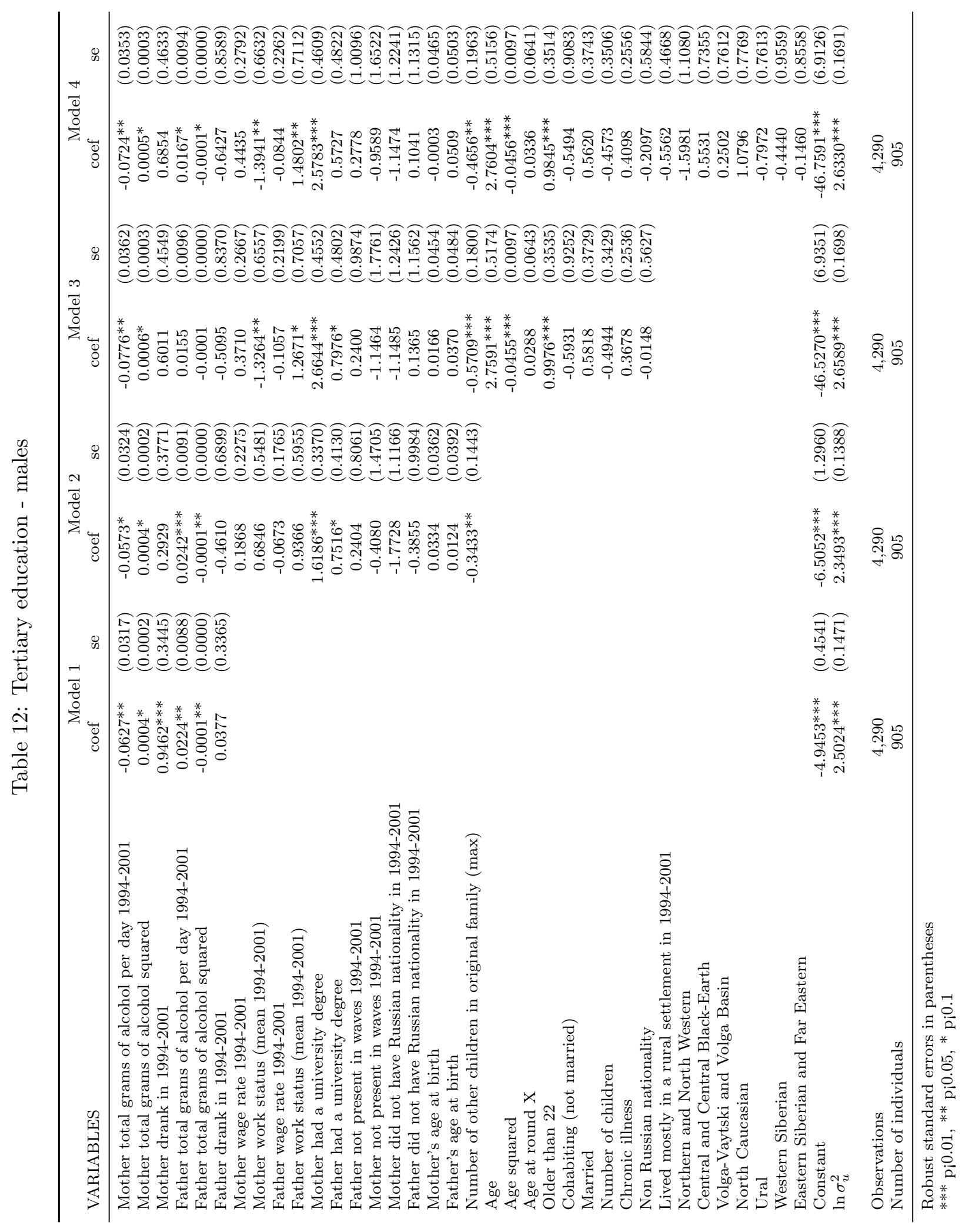




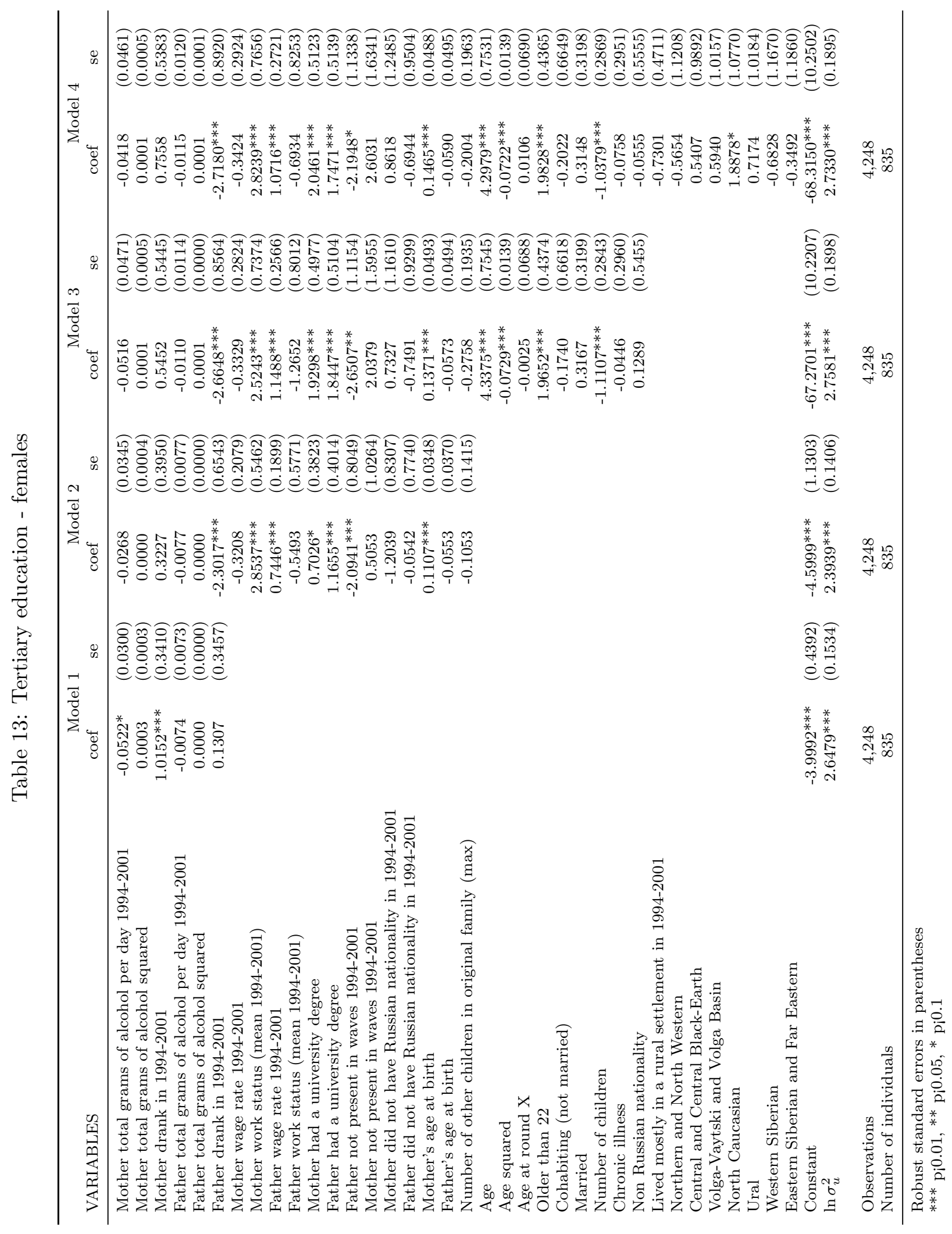




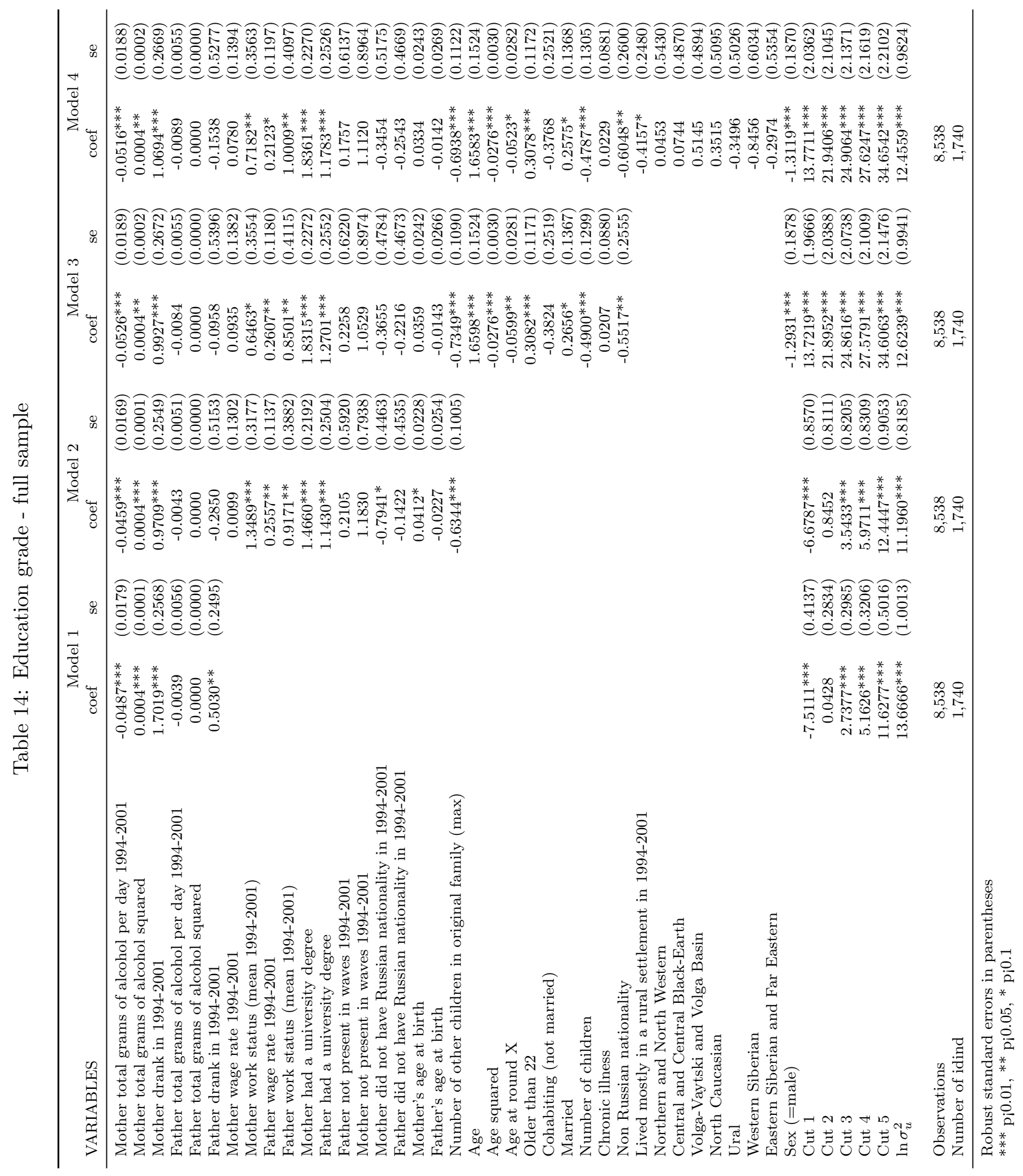




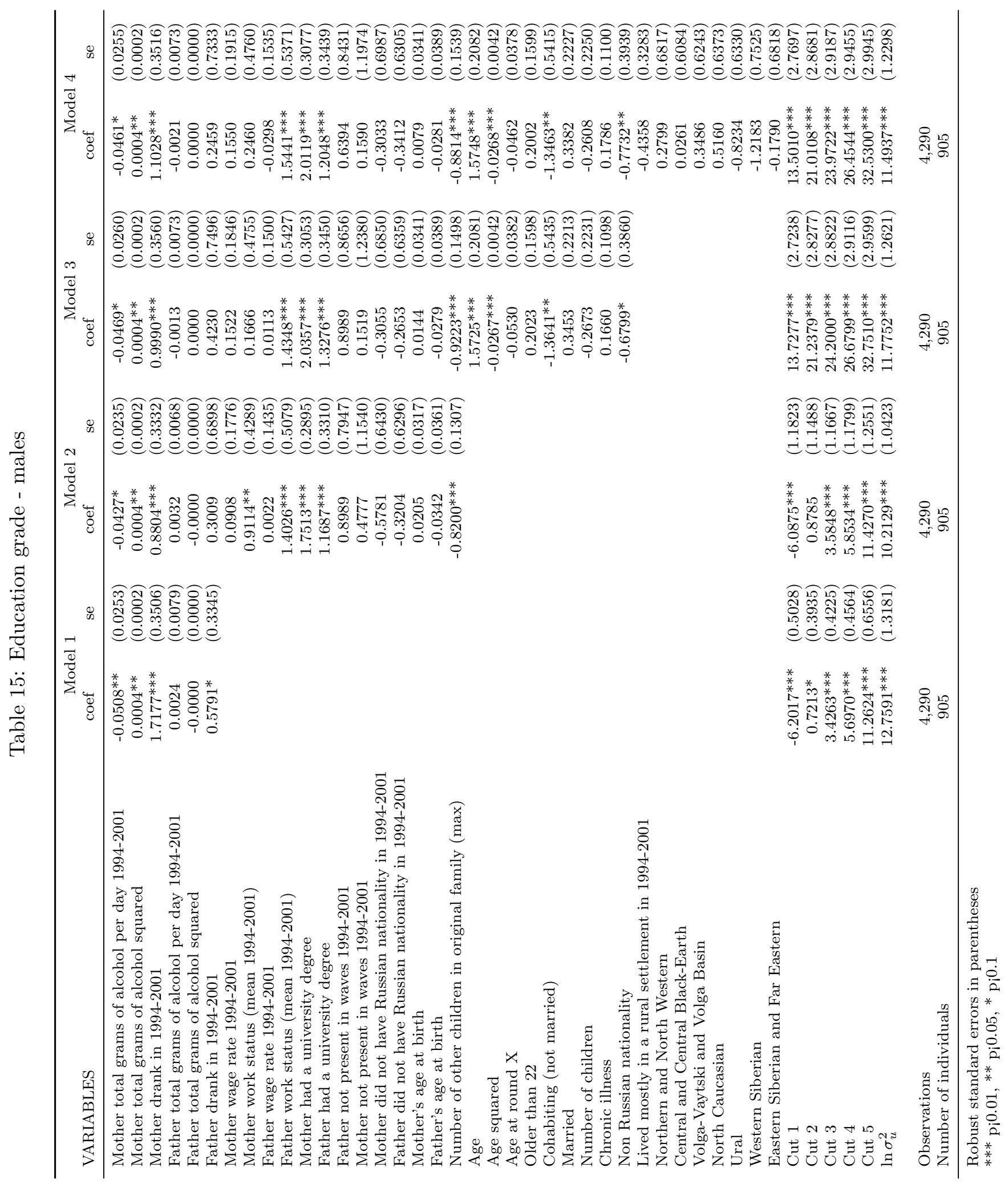




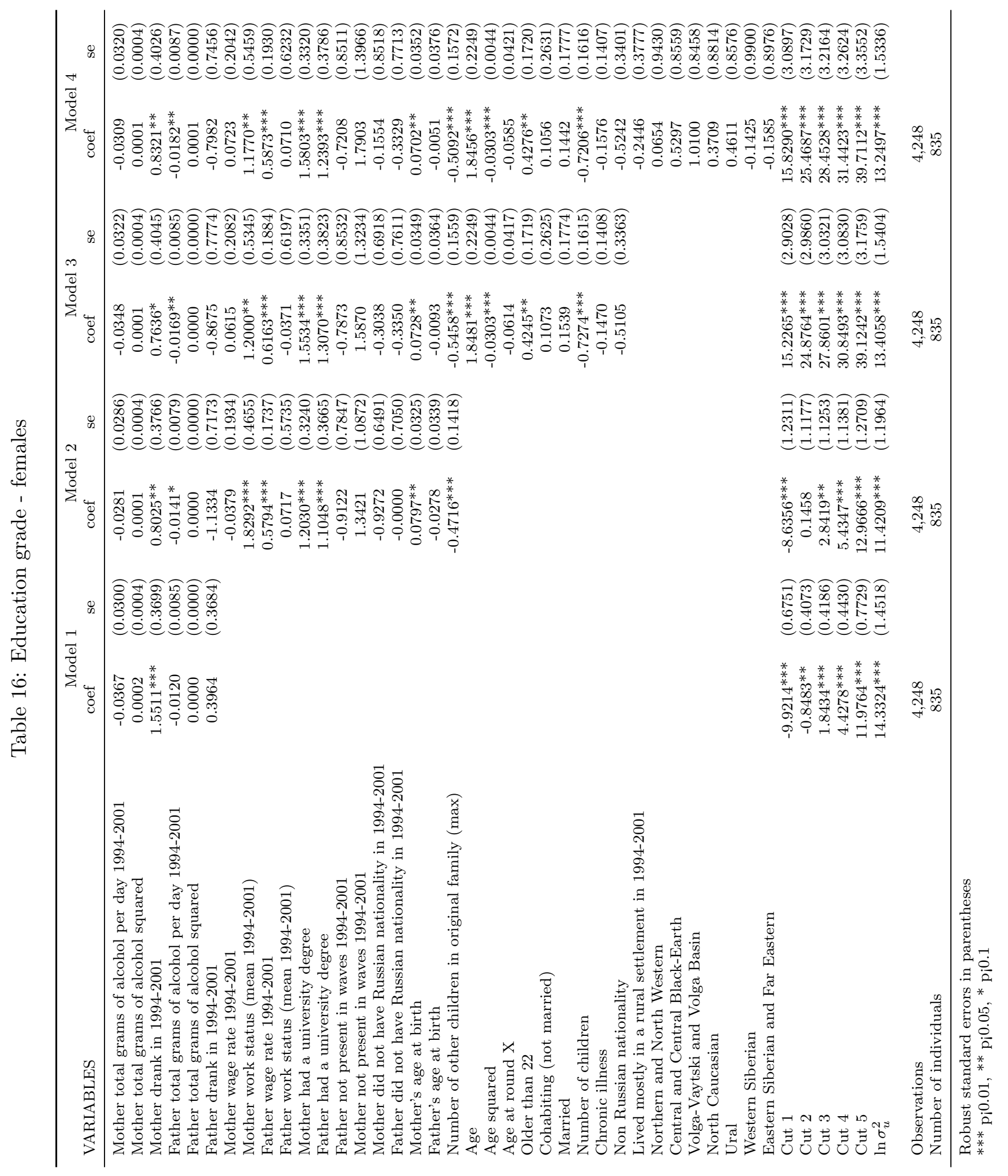




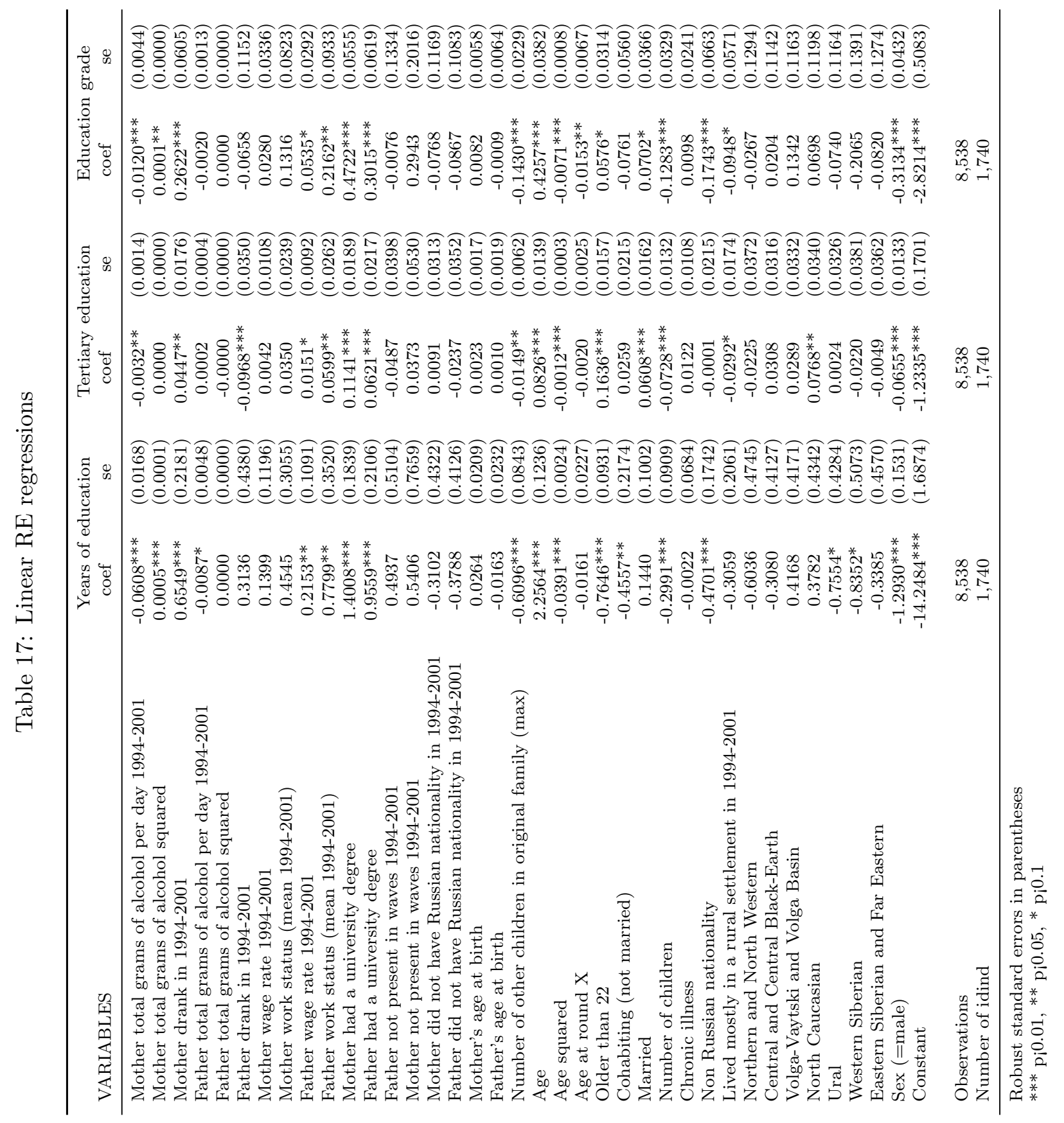




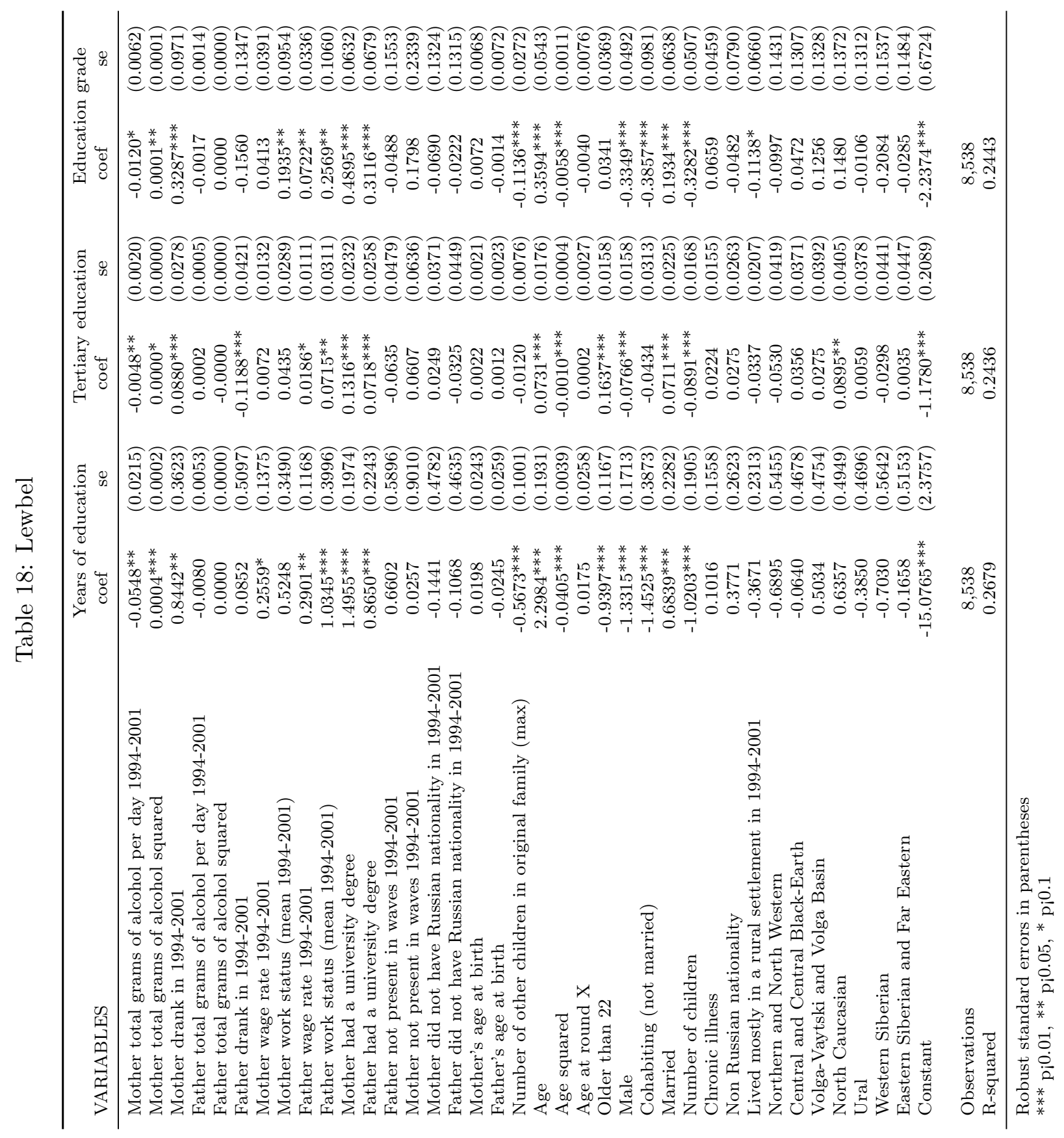




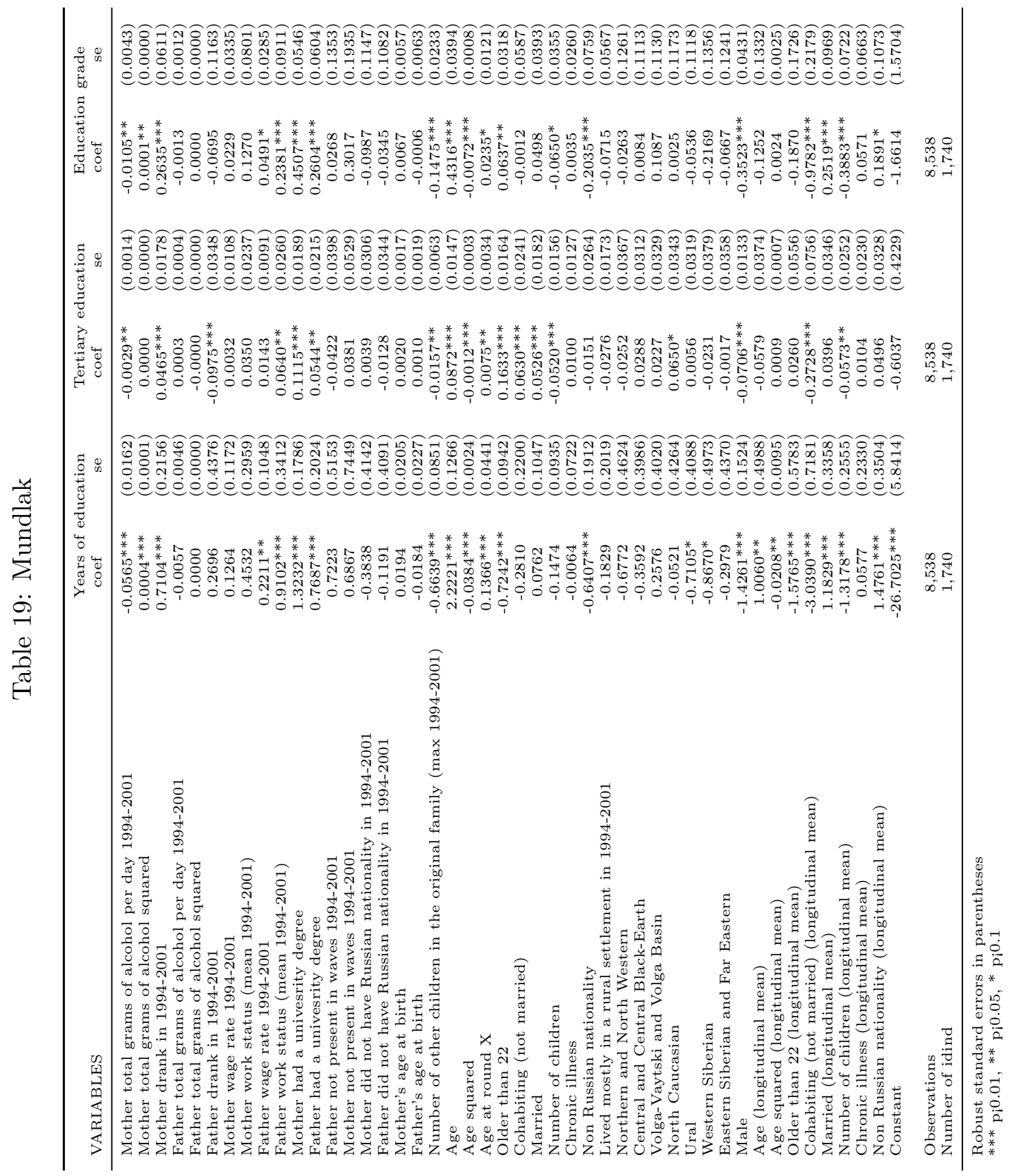




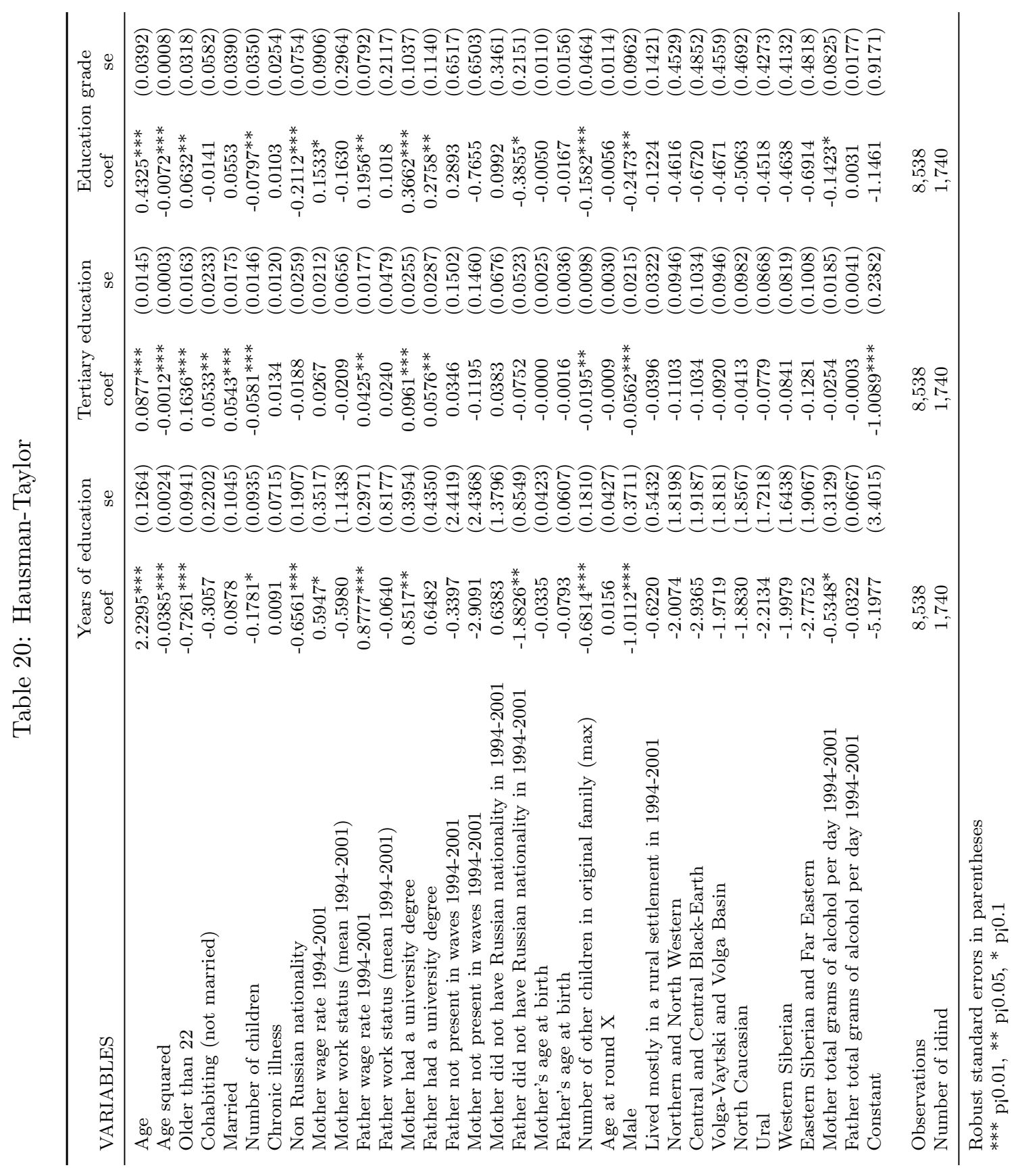

